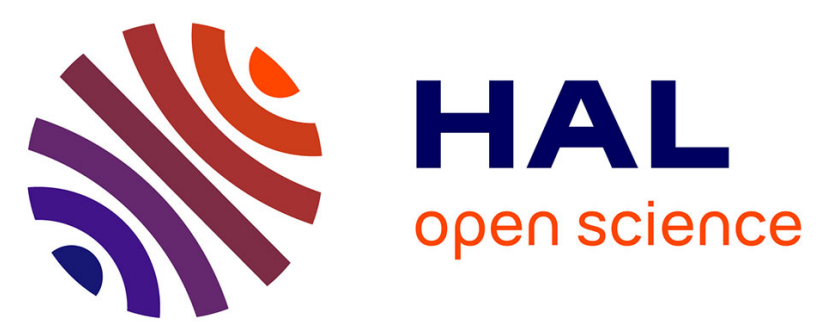

\title{
Chapitre VI - L'image sociale et culturelle des pratiques funéraires: expressions et évolutions de la société romaine dans le sud-est de la Gaule
}

Frédérique Blaizot

\section{- To cite this version:}

Frédérique Blaizot. Chapitre VI - L'image sociale et culturelle des pratiques funéraires: expressions et évolutions de la société romaine dans le sud-est de la Gaule. Gallia - Archéologie de la France antique, 2009, Pratiques et espaces funéraires de la Gaule durant l'Antiquité, 66 (1), pp.311-343. 10.3406/galia.2009.3377 . hal-01911024

\author{
HAL Id: hal-01911024 \\ https://hal.science/hal-01911024
}

Submitted on 7 Jan 2020

HAL is a multi-disciplinary open access archive for the deposit and dissemination of scientific research documents, whether they are published or not. The documents may come from teaching and research institutions in France or abroad, or from public or private research centers.
L'archive ouverte pluridisciplinaire HAL, est destinée au dépôt et à la diffusion de documents scientifiques de niveau recherche, publiés ou non, émanant des établissements d'enseignement et de recherche français ou étrangers, des laboratoires publics ou privés.

\section{(ㅇ)(1) $\$$}

Distributed under a Creative Commons Attribution - NonCommercial - NoDerivatives 44.0 


\title{
L'IMAGE SOCIALE ET CULTURELLE DES PRATIQUES FUNÉRAIRES : EXPRESSIONS ET ÉVOLUTIONS DE LA SOCIÉTÉ ROMAINE DANS LE SUD-EST DE LA GAULE
}

\author{
Frédérique BLAIZOT
}

\section{LA VALEUR SOCIALE DES PRATIQUES FUNÉRAIRES : QUELLES PERSPECTIVES?}

En introduction de cet ouvrage, nous avons défini les objectifs de notre recherche qui sont de recentrer nos questionnements sur le mort et la mort, à la fois objets et sujets du rituel. Recueillir les éléments des dispositifs funéraires et en réaliser l'interprétation fonctionnelle peut constituer un but en soi ; ils nous éclairent sur des aspects laissés dans l'ombre par les textes et l'objectif palethnologique de la démarche peut ainsi se suffire à lui-même. Mais on peut aussi s'interroger sur le sens et la fonction du système que ces dispositifs retranscrivent dans un contexte donné ; en l'occurrence, pour celui qui nous occupe ici, la question porte sur la manière dont le système élaboré par la société antique exalte et assure la continuité de certaines valeurs sociales et facilite la transmission de la mémoire des communautés.

Or, à quoi sert l'étude des pratiques funéraires de la société romaine, dans la mesure où les données textuelles nous informent déjà sur les grandes lignes de leurs séquences et sur leur rôle social ? En quoi les données archéologiques produisent-elles une connaissance différente des sociétés de celle qui est fournie par les textes ? Ces questions transcrivent tout l'embarras de l'archéologie des contextes historiques : d'un côté, on trie dans les données archéologiques celles qui sont susceptibles d'argumenter ou d'éclairer les changements sociaux ou historiques perçus ou connus par d'autres sources ; d'un autre côté, on tente au moyen de ces dernières, toujours allusives et imprécises, de réaliser l'interprétation sociale et historique de certaines configurations relevées en contexte archéologique dont l'interprétation s'avère le plus souvent problématique.

La contribution de l'étude des pratiques funéraires à la connaissance des sociétés anciennes est ambiguë, d'abord parce que la notion même «d'interprétation sociale » est équivoque. Si l'impact des orientations qui ont marqué la révolution de la pensée archéologique à partir des années 1960 est resté faible sur l'archéologie métropolitaine (Scarre, 1998), et sur les contextes de l'Antiquité en général (comme en témoigne le texte tardif de R. Étienne, 1992), l'archéologie funéraire dans ses visées actuelles, leur est toutefois redevable à plus d'un titre. Rappelons, pour ce qui concerne ce domaine, que les archéologues américains, dont P. Ucko (1969), A.-A. Saxe (1970), L. Binford (1971) et J.-A. Tainter (1975) sont les porte-paroles, fondent leur réflexion sur le principe que l'organisation d'un cimetière reflète celle de la société vivante ; de ce fait, toute modification du système social entraîne une modification des pratiques funéraires. Ainsi, dans ce courant théorique, l'étude des pratiques funéraires a pour ambition d'appréhender le degré de complexité sociale du groupe, que l'on propose de mesurer en élaborant des modèles explicatifs de l'évolution des sociétés. Cependant, le retour aux données 
ethnologiques et, plus largement, l'émergence de l'ethnoarchéologie en France (Aurenche, 1985 ; Lerclerc, 1988 ; Gallay, 1992), plus que d'avoir fourni les éléments d'interprétation en ce sens, ont contribué à mettre en évidence les limites de la représentativité du document archéologique et à prendre conscience de l'importante distorsion qui existe entre le monde réel et le monde des morts. Ceci fut presque l'aveu d'une impasse : loin de pouvoir explorer toutes les dimensions du domaine funéraire, et encore moins toutes celles du domaine social (Balut, 1992), l'archéologie funéraire devait recentrer ses objectifs.

Récemment, l'aporie de l'exercice a été plus particulièrement soulignée pour la Gaule romaine par A. Ferdière (Ferdière, 2004). L'ensemble des contre-exemples opposés par l'auteur peut être résumé au fait que ni les pratiques funéraires, ni les structures sociales ne constituent un système figé et monolithe, mais un cadre défini par des choix culturels, des règles, des rôles et des relations dont les modes d'expression sont soumis à une importante variabilité et à de fréquents réajustements. A. Ferdière évoque également la confusion opérée entre une tombe " riche » (moyens mis en ouvre) et une tombe « de riche » (qui se réfère au statut), dénoncée également par L. Baray pour le second âge du Fer (Baray, 2002), et rappelle, à juste titre, que la tombe n'est qu'une partie du support des rites funéraires, la personne sociale pouvant être exprimée à diverses étapes de la cérémonie (la part des invités, le bûcher...), ou par d'autres marqueurs que le mobilier, parmi lesquels certains n'ont d'ailleurs pas toujours survécu (stèles, monuments). Il aborde également la difficulté à associer la pléthore de tombes dispersées aux établissements ruraux qui nous prive à jamais d'accéder à l'organisation des populations.

Nos données cumulées s'accordent tout à fait à l'ensemble de ses arguments. Pour l'époque romaine, les notions de nature et de richesse du mobilier sont inopérantes pour tenter de distinguer les catégories sociales ou d'établir une hiérarchie au sein d'un groupe de tombes, mis à part quelques cas exceptionnels, rencontrés surtout jusqu'au premier tiers du $\mathrm{I}^{\mathrm{er}}$ s. dans le nord de la Gaule et une poignée d'exemples tardifs isolés. Les différences dans la mise en œuvre de l'appareil funéraire ne peuvent être perçues que par bribes : présence de grands bûchers ostentatoires, tant en contexte urbain qu'en contexte rural où ils sont indéfectiblement liés aux grands domaines, profusion de vaisselle, constructions de grands mausolées situés dans des lieux stratégiques... Mais tout cela ne constitue qu'une partie de l'organisation funéraire qui, en outre, est déterminée culturellement par les microcontextes chronologiques et régionaux. En dehors des inscriptions et des monuments, les rares informations fournies en ce sens par les objets sont en effet ponctuelles et donc anecdotiques puisque, hormis la vaisselle ordinaire et identique à celle de la sphère domestique, le matériel se rapporte au mieux à une activité précise (un métier, un passe-temps), à une classe d'âge, un sexe, ou bien ne possède qu'une valeur affective... Tout au plus, l'incroyable diversité et la grande banalité de toute cette panoplie nous enseignent que ces éléments n'ont pas valeur de symbole statutaire dans le discours funéraire romain, mais participent du libre choix de chacun. Parmi les codes, certains ne font que traduire la liberté qu'autorise le système relativement aux exigences du rituel, même s'ils constituent toutefois par cela une source de renseignements sur la valeur sociale des pratiques funéraires, mais dans un autre registre (voir infra, p. 335-343). Par ailleurs, dans la mesure où le mobilier est surtout mis en œuvre sur le bûcher et que, selon les cas, ses vestiges sont associés en partie, voire ne sont pas associés aux ossuaires, les données s'avèrent à la fois incomplètes et hétérogènes en fonction des modalités de la dévolution des résidus. Enfin, pour ce qui concerne l'organisation des morts, nous avons évoqué plus haut les écueils rencontrés, dès lors que l'on tente de répondre à la question du recrutement des ensembles funéraires et du statut des individus qui les composent (voir chapitre V). Où sont les notables, les citoyens ordinaires, les esclaves, les étrangers... ? Le plus souvent, ne jaillit du sol qu'une poignée d'ossements calcinés ou ne s'ouvre qu'une tombe muette, les inscriptions ayant depuis longtemps disparu. Plus largement, la discussion relative à la hiérarchisation sociale des espaces funéraires dans une ville comme Lyon ne saurait ignorer que des stèles et des monuments furent récupérés durant l'Antiquité tardive. Ainsi, sauf cas exceptionnels de conservation, les règles qui régissent le recrutement des lieux sépulcraux nous échappent. Par ailleurs, la dynamique de la plupart des ensembles funéraires urbains et ruraux, inconstante et saltatoire, conjuguée aux habituelles contraintes spatiales des investigations archéologiques et à l'imprécision de nos évaluations chronologiques, ne nous facilite pas la tâche. S'il nous apparaît qu'à la répartition spatiale des vivants correspond généralement celle des morts, les lieux d'inhumations durent le temps que survit la mémoire du noyau fondateur, du groupe d'origine, sans doute cristallisée par le lieu d'habitation des vivants ; ainsi, un espace funéraire ne renvoie qu'à un moment donné de l'histoire d'un habitat, dont nous avons du mal à définir la place, le statut et la durée, sachant en outre que les propriétés des domaines suburbains, par exemple, changent souvent de main (Lafon, 2002, p. 114). Au final, on ne dispose que d'informations aléatoires et isolées, 
offrant une vision terriblement limitée de la société romaine telle qu'on la connaît par d'autres sources.

L'ouverture de l'archéologie à l'interdisciplinarité, au moment même où se renouvelaient les problématiques archéologiques propulsées par l'accroissement des données, a été l'occasion de se réinterroger sur la finalité des fouilles de sépultures. En développant diverses approches du type de celles présentées dans les chapitres précédents, l'archéologie funéraire a repris sa place en tant que thématique archéologique, dans le sens où les données qu'elle produit sont mises en relation pour définir les différents comportements des sociétés envers les morts. La question du rapport de la société à ses morts est alors examinée dans d'autres perspectives que celles qui consistaient à préciser la structuration de la société des vivants, puisqu'il s'agit de considérer la société des morts comme un monde en soi pourvu de sa propre image sociale, élaborée en pratiquant une sélection parmi les valeurs de la collectivité. Il va sans dire que cette image reflète plus l'organisation idéale que l'organisation réelle de la société et, par extension, que le monde funéraire nous renseigne moins sur la structuration des vivants que sur les pratiques sociales et, plus particulièrement, sur les rapports que les individus entretiennent avec l'idéologie sociale. Étudier ces comportements revient ainsi à s'intéresser à la manière dont les individus quittent le monde des vivants et s'y réintègrent en tant que défunts ; en dernière analyse, l'objectif est de mettre en évidence le système culturel par lequel les sociétés se sont organisées pour permettre le passage de l'avant à l'après et, par cela même, pour assurer leur survie (Leclerc, 1996).

La question des pratiques funéraires romaines ne peut être abordée sans avoir en permanence à l'esprit les trois registres qui sont impliqués dans la construction du système : la réalité économique et sociale, l'idéologie religieuse et le poids des traditions. Nous avons ci-dessus défini l'orientation dans laquelle nous souhaitons engager l'interprétation sociale des pratiques, à savoir dans une perspective dynamique par laquelle la société construit son image et rétablit l'ordre des choses. Dans ce cadre général, quasi universel, rappelons que les religions romaines s'opposent fondamentalement à celles qui impliquent un système de croyances destiné à assurer le salut de l'homme et de son âme par-delà la mort. Ritualistes et traditionalistes, dépourvues d'une doctrine unique et contrôlée, elles sont conçues comme un ensemble de pratiques privées qui régissent les relations sociales de la communauté dans tous leurs aspects, dans le sens où elles assurent la continuité du code social de la cité et la liberté des membres de cette dernière, en respec- tant et en rappelant les engagements mutuels des hommes et des dieux (Scheid, 1998). C'est là que se situe tout leur paradoxe : plutôt qu'universelle, la norme religieuse est liée aux communautés tout en étant commune aux cités ${ }^{36}$. Elle se pose ainsi davantage en tant que règle contingente, puisqu'elle ne définit aucune des modalités des rites, mais se contente d'en fournir le cadre formel général. Dans le domaine funéraire comme dans l'ensemble des actes communautaires, la religion est donc surtout une « affaire de rites » (Scheid, 2005, p. 208), par lesquels on exprime un modèle culturel, un idéal social garantissant et restaurant l'ordre établi, plutôt qu'une assurance métaphysique. Le rite funéraire romain est un rite domestique, célébré par la personne qui détient l'autorité familiale et a deux objectifs directs. L'un est de purifier la famille souillée par la mort et l'autre est de faire entrer le défunt dans le groupe des Dieux mânes, ce qui implique un certain nombre de devoirs envers les divinités et laisse envisager que les gestes funéraires ne transcrivent pas uniquement des actes en relation avec le seul défunt. Par ailleurs, au cœur de ce système borné par les devoirs, les supports du rite s'articulent en un ensemble de gestes, de paroles et d'attitudes dont le principe est immuable, mais dont l'expression peut varier selon les contextes et les traditions culturelles, et évoluer dans le temps. Ces notions sont particulièrement cruciales dans le cadre qui nous occupe, d'une part parce que les faits examinés se sont produits en Gaule, région au substrat culturel diversifié, et d'autre part parce que nous raisonnons à partir de données archéologiques, c'est-à-dire de témoins fragmentaires et discontinus.

L'objectif des réflexions qui vont suivre est de proposer une lecture des gestes et des pratiques comme une succession d'intégrations, de réinterprétations et d'innovations au sein d'un cadre général qui apparaît en constant rééquilibrage. C'est en ce sens que les pratiques et leurs rythmes transcrivent l'ensemble des rapports sociaux d'une communauté à un moment donné, à la fois à l'intérieur de celle-ci et entre les groupes qui la constituent. Nous proposons pour cela d'analyser nos données en deux étapes. La première tente de restituer, au moyen des données archéologiques, le déroulement du rite funéraire qui est célébré sur le lieu de traitement du corps, de dépôt des restes et de commémoration du défunt. Il s'agit là d'interpréter les configurations relevées en termes de gestes, et de les ordonner de manière

36. J. Scheid, «Introduction à la notion de norme religieuse ", communication donnée au colloque organisé par B. Cabouret et M.-O. Laforge (dir.), La Norme religieuse dans l'Antiquité, 14-15 déc. 2007, Maison de l'Orient méditerranéen, Lyon. 
à les inscrire dans la logique du rituel, les funérailles étant définies par un ensemble dynamique de pratiques. Le plan adopté dans les quatre premiers chapitres préfigure cette organisation, puisqu'il présente, autant que faire se peut, les faits selon l'ordre le plus probable dans lequel ils se sont déroulés. La deuxième étape consiste à examiner la variabilité et l'évolution des pratiques en incluant les données de l'âge du Fer et de l'Antiquité tardive, afin d'analyser, sous l'angle des rapports sociaux, le développement sur la durée des systèmes funéraires mis en évidence pour les trois premiers siècles de notre ère.

\section{FRAGMENTS DU SYSTÈME FUNÉRAIRE : LES ÉTAPES MISES EN ÉVIDENCE DANS LE QUART CENTRE-SUD-EST DE LA GAULE}

\section{CE QUE RACONTENT LES TEXTES}

Les textes antiques portent sur les séquences du rite funéraire dont l'enjeu social est important pour la communauté : l'exposition, le cortège funèbre la laudatio et les monuments (Scheid, 2005, p. 164) ; en revanche, les témoignages écrits sur le déroulement effectif (privé) des funérailles sont quasi inexistants, tout comme le sont ceux qui se rapportent aux différents rites de commémoration. Nous ne reprendrons pas l'inventaire des maigres informations dont on dispose, puisqu'elles ont été présentées et discutées par J. Scheid en 1984 ; le fait qu'elles tiennent sur une seule des vingt-trois pages qui constituent l'article donne la mesure de l'imprécision des sources qui s'y rapportent (Scheid, 1984, p. 127-128). Rappelons toutefois la part importante que prennent, au moment des funérailles, le sacrifice d'une truie à Cérès destiné à purifier la famille, et le banquet funéraire (silicernium) dressé pour les vivants sur une table à proximité et placé pour le mort sur le bûcher. Or, le sacrifice romain étant avant tout un banquet au cours duquel les convives mangent avec le mort et les dieux, il est logique d'envisager que les morceaux de la truie sont partagés entre les différents partenaires du sacrifice, à savoir la déesse Cérès, le mort et les invités, les Dieux mânes étant bien entendu exclus de ce partage.

Huit jours après la cérémonie, après l'enfouissement des restes du défunt, deux autres sacrifices s'inscrivent dans la séquence du deuil dont ils marquent la fin (Scheid, 2005, p. 177). L'un est un holocauste dédié aux Mânes du mort, destiné à faire entrer le défunt dans le groupe des Dieux mânes et l'autre, familial, est offert au Lare de la maison ou aux Pénates, de manière à ce que la famille retrouve sa place parmi les vivants (id., ibid., p. 186). Si le premier est effectué près de la tombe, les textes ne précisent pas où se tient le second, qui implique un partage exclusif entre la famille et le dieu domestique. Toutefois, un texte d'Ovide se rapportant au banquet de commémoration du mort, supposé reproduire les sacrifices de la neuvaine (Feralia), laisse envisager qu'un banquet se tenait près de la tombe (id., ibid., p. 181).

Ainsi, des holocaustes offerts aux divinités de l'en-bas jusqu'aux banquets partagés entre le mort, les vivants et les dieux non infernaux, c'est toute la structure sociale et cosmogonique qui est représentée tout au long des funérailles.

\section{SYNTHÈSE DES DONNÉES ARCHÉOLOGIQUES}

Les données archéologiques des régions étudiées permettent de décrire les faits suivants.

\section{LA GRÉMATION}

Le mort est installé sur le bûcher parfois sur un lit, parfois sans doute dans un cercueil. Le bûcher lui-même s'apparente, dans certains cas, à une véritable construction souvent décorée, dont la restitution exacte reste sujette à caution (monument réel ou base d'une plate-forme ?). Il peut être aérien ou bien pratiqué dans une grande fosse rectangulaire.

Des récipients, des viandes, des fruits, des céréales, du pain, des gâteaux et autres préparations alimentaires, des liquides, des vases à parfum, parfois quelques objets personnels et des lampes, sont disposés sur le bûcher. Ils sont manifestement classés et présentés de manière rationnelle, par catégories et sur des supports étagés, à côté du corps ou bien au-dessous, mais jamais au-dessus, le mort restant l'élément central du dispositif. Les vases, dont certains sont brisés intentionnellement avant d'être brûlés, correspondent à de la vaisselle de table, majoritairement destinée aux nourritures solides, mais les vases à liquides sont rencontrés dans des proportions variables selon les régions. Très peu, voire aucun récipient ou ustensile lié à la préparation ou à l'organisation du banquet sont placés sur les bûchers. Le Porc constitue la majeure partie des animaux sélectionnés, même s'il est loin d'être exclusif, et est principalement illustré par le jambon, la tête ou les pieds, comme le montrent les cas où l'étude des os a été réalisée (en Auvergne notamment) ${ }^{37}$.

La mise à feu est effectuée et la crémation commence, celle-ci pouvant être active (conduction) ou passive.

37. Études de P. Caillat, Inrap. 
Une fois la crémation achevée, des os sont récoltés en quantité variable selon les cas, sachant que dans certains d'entre eux, la masse osseuse relevée, compatible avec les données théoriques d'un individu adulte complet, ne permet pas de prouver qu'un prélèvement a eu lieu. Le ramassage peut se faire directement dans la fosse (comme le montre le bûcher de Chartres) ou bien à l'extérieur ce qui implique d'avoir extrait les résidus en masse dans un premier temps (la Raude à Tassin-la-Demi-Lune ; bûcher 1154 du 78 rue Jean-Jaurès à Nîmes). Dans les bûchers en fosse, il arrive que l'ensemble de la couche de crémation soit réagencée, voire intégrée dans un dispositif architectural, même après que des prélèvements, destinés à constituer l'ossuaire, aient été effectués. Certains exemples attestent de bris de cruches, plus rarement d'amphores, dont les fragments sont en partie rejetés en surface de la couche de crémation. Dans d'autres cas, des vases complets non brûlés sont déposés au sommet de cette couche ainsi que, très exceptionnellement puisqu'un seul site est concerné, des objets de toilette ou des outils ou de la faune. Les récipients se composent quasi exclusivement de vases à liquides, de lampes ou de balsamaires, les vases à solides étant représentés sur deux sites seulement.

La dernière séquence se rapporte à la condamnation du bûcher, qui semble marquée de différentes manières. Certains paraissent avoir été laissés ouverts, d'autres remblayés volontairement et parfois surmontés d'une couche de blocs, d'autres encore sont fermés d'une couverture de bois, de tegulae ou de dalles. Quelques structures sont équipées d'un conduit à libation, d'autres d'un dispositif de signalisation.

\section{LA CONSTITUTION DU LIEU DE DÉPÔT DÉFINITIF DES RESTES}

L'enfouissement des restes ou plutôt d'une partie des restes du défunt, constitue la deuxième étape fondamentale du rite funéraire ; ce geste confère aux restes le statut de sépulture et à cette dernière celui de droit sacré, ce qui signifie qu'elle devient propriété des dieux (en l'occurrence celle des Dieux mânes, dont le droit est garanti par la cité).

Les données archéologiques rendent compte de deux unités distinctes, qui peuvent être réunies ou non dans une même fosse : l'ossuaire et les résidus. On notera que les textes qui évoquent la constitution de la tombe ne disent nul mot des dépôts de résidus : dans tous les cas, ils se réfèrent à la collecte des seuls ossements qui sont lavés avec du vin, puis placés dans un contenant. Le dépôt de l'ossuaire se fait dans une fosse pratiquée expressément ou bien, plus rarement, dans le bûcher. Doit-on supposer qu'il en est de même pour les dépôts de résidus, ce qui serait illustré alors par les cas de réagencements de la couche de crémation dans les bûchers en fosse?

Contrairement à la fosse qui contient les seuls résidus, celle qui reçoit l'ossuaire s'avère souvent architecturée (de la simple couverture à la construction complète) et organisée au moyen de dispositifs variés (coffre ou grande céramique renfermant le vase ossuaire, répartition spatiale différenciée de l'ossuaire et des autres dépôts, objets et/ou résidus, par étagement ou cloisonnement). Elle est pourvue d'un conduit à libation illustré par une céramique percée ou suggéré par la perforation du couvercle de l'ossuaire ; on peut envisager un dispositif en matériau périssable pour celles qui n'en conservent pas les traces. L'ossuaire est le plus souvent pratiqué dans un vase, dont la panse peut avoir été percée, et est fermé par un couvercle muni d'un orifice ou par un élément amovible (caillou...), de manière à introduire un conduit pour les libations. Les dépôts de résidus ne sont qu'exceptionnellement placés dans un contenant. Les os qui constituent l'ossuaire ne semblent pas, dans la très grande majorité des cas, sélectionnés sur le critère d'une région anatomique. Quelques exemples suggèrent qu'ils sont placés dans un sac avant d'être déposés dans le vase ossuaire. Dans les dépôts antérieurs au $\mathrm{II}^{\mathrm{e}}$ s., des balsamaires sont fréquemment associés aux ossements et plus rarement des vases liquides, des petits objets personnels ou des aliments. Le mobilier primaire peut être réintroduit de manière explicite dans la structure de dépôt : regroupé au sein des résidus ou bien associé à l'ossuaire. Dans la plupart des cas toutefois, le mobilier déposé dans la tombe, dont la présence n'est pas systématique, ne provient pas du bûcher. Il s'agit majoritairement de vases, parmi lesquels ceux dévolus au service des liquides sont en bonne place, notamment s'ils sont placés au contact de l'ossuaire (régions non méridionales). Ces récipients, notamment les cruches, s'avèrent être pour la plupart mutilés. Les vases à solides contiennent parfois des dépôts alimentaires. La situation des divers récipients est variable : certains reposent debout, d'autres, comme les vases à liquides, semblent avoir intentionnellement été placés à l'envers comme pour en déverser le contenu, tandis que d'autres vases à liquides ou des balsamaires ont été brisés sous ou à côté du vase ossuaire.

\section{LA PRATIQUE DE L'INHUMATION}

Un recueil de textes antiques établi par C. Vismara montre que presque aucune source romaine ne décrit, voire 
n'évoque explicitement, la pratique de l'inhumation au quotidien, l'ensevelissement étant mentionné de manière générique, sans qu'il soit possible de distinguer si les auteurs se réfèrent à des os calcinés ou à un cadavre (Vismara, 1991). Les textes qui concernent l'Orient n'offrent pas davantage de précision.

Les inhumations concernent un nombre restreint d'individus, mais la quasi-totalité des sujets décédés en phase infantile, ainsi que les chiens. Les modes d'inhumation se caractérisent par une importante variabilité, exprimée par l'attitude des corps au Haut-Empire et par l'architecture mise en œuvre tout au long de l'Antiquité. Ce qui distingue significativement les deux rites est que la fréquence et l'abondance du mobilier primaire, relevées dans les couches de crémation, ne sont pas transposées dans les tombes à inhumation, puisque l'ensemble de nos séries livre un peu moins de $20 \%$ de sépultures pourvues de vases. Les proportions se rapprochent plus de celles du mobilier secondaire des structures de dépôts de crémation, d'autant plus qu'elles varient de manière équivalente dans le temps. Les fonctions représentées par les vases apparaissent assez diverses, mais globalement, le service des liquides est majoritairement illustré. La même diversité apparaît dans les tombes de l'Antiquité tardive, tant pour ce qui concerne la fréquence et l'abondance des dépôts que pour les fonctions représentées par les vases, bien que celle des liquides apparaisse prédominante, surtout pour la fin de la période. Les vases portent souvent des mutilations, à l'instar de ce qui est relevé dans les dépôts de crémation et, dans les cas où le mobilier est en grand nombre, ils présentent des relations variées avec le corps : dépôt dans la tombe, à l'intérieur ou à l'extérieur du contenant, sur le fond ou sur des présentoirs, ou encore sur le couvercle, rejets de vases brisés hors de la tombe ou bris pratiqués sur le couvercle du contenant. La disposition générale des vases varie selon leur fonction, avec des modalités diverses selon les groupes. Les conduits à libation sont exceptionnels, sans doute parce que la plupart des dispositifs étaient en matériau organique.

\section{LE STATUT DES BÛCHERS, DES FOSSES À RÉSIDUS ET LA NOTION DE SÉPULTURE}

La caractéristique principale qui ressort de l'ensemble des structures et des gestes présentés dans les chapitres précédents est la diversité ; celle-ci s'exprime dans la manifestation de tel ou tel fait et dans les configurations relevées, que ce soit au sein d'une même ville ou d'une même région, qu'entre différents secteurs géographiques. Cette importante varia- bilité rend malaisée, à l'heure actuelle, le mise en évidence des tendances générales au sein des régions, ce qui ressort également de l'examen des séries de Suisse occidentale (Castella et al., 1999, p. 48). L'essentiel de la difficulté réside donc dans le classement de ces manifestations, nécessaire à l'interprétation de leur rôle au sein du système funéraire.

Les dernières avancées de la recherche montrent que toutes les structures funéraires liées à la crémation rencontrées à l'époque romaine existent bien avant la conquête. Dès l'âge du Bronze, des bûchers en fosse conservent les restes calcinés du squelette en situation de logique anatomique, auxquels le statut de tombe est accordé par nos collègues (Le Goff, Guillot, 2005). Les bûchers de type Laufeld, du premier âge du Fer, ou ceux pratiqués en Macédoine aux VI ${ }^{\mathrm{e}}-\mathrm{V}^{\mathrm{e}}$ s. (Guimier-Sorbets, Morizot, 2005, p. 139), sur lesquels un tumulus est érigé, paraissent encore plus explicites, tandis que la question se pose pour certains contextes du IX ${ }^{\mathrm{e}}$ s. à Chos, en Crète et sur la côte thrace (Polignac, 2005, p. 177). Enfin, les données récentes des régions Rhône-Alpes et Auvergne fournissent des exemples d'ossuaires pratiqués dans des bûchers en fosse au $\mathrm{II}^{\mathrm{e}}$ s. av. J.-C. (données inédites des sites de Bel Air à Saint-Laurent-la-Conche dans la Loire et de la Cime des Bruyères à Pulvérières dans le Puy-deDôme). Aux âges du Bronze et du Fer, les structures secondaires possèdent des dispositifs proches, relevés selon la même variabilité : dépôts en ossuaire (en céramique et/ou en matériau périssable), dépôt de résidus et dépôts mixtes (Flouest, 1993 ; Taffanel et al., 1998 ; Mazières, 2002 ; Blaizot, Georjon, 2005 ; Delattre, Peake, 2005 ; Le Goff, Guichard, 2005). Généralement, toutes ces structures de dépôt sont interprétées comme des tombes.

Toutefois, la complexité des faits mise en évidence nous invite à nous demander si, dans l'Antiquité, chacune de ces structures désigne véritablement la même chose. Ces dernières années, nous avons tout particulièrement réfléchi à la question de la place des différentes structures et de leurs composantes dans les funérailles de l'Antiquité (Bel et al., 2002 ; Blaizot, Tranoy, 2004 ; Richier, 2005 ; Blaizot, Bonnet, 2007 ; Blaizot et al., 2007), en développant notamment les questions suivantes : quelle est la valeur, symbolique et fonctionnelle, du bûcher en fosse ? Le dépôt de résidus illustret-il le même geste que le dépôt en ossuaire ? Tous les dépôts de résidus participent-ils de la même intention ? Que représentent les céramiques intactes ou lacunaires, entières ou brisées dans les différentes structures ? Au final, la question est de savoir à quelles étapes de la cérémonie funéraire de la crémation correspondent les différents gestes que l'on peut restituer par les vestiges archéologiques. 
Avant de discuter la signification des gestes relevés dans les structures archéologiques, il est essentiel de revenir sur le problème relatif au statut de certaines structures, et tout particulièrement celui des bûchers en fosse. En effet, un certain nombre de questionnements relatifs à la valeur des différents dépôts (humains, faune, vaisselle) effectués au cours du déroulement des funérailles ne peuvent être compris sans que la notion de sépulture et les structures qui semblent s'y rapporter soient définies.

Pour les Romains, la tombe est, a priori, comme dans nos sociétés modernes, ce qui désigne le mort et plus précisément, ce qui atteste des rites accomplis et à accomplir, supports de la mémoire du défunt. Dans cette société, la sépulture, de statut religieux, est effective à deux conditions : la première est d'accomplir le sacrifice du porc et la seconde, de répandre de la terre sur des os, voire sur un os : "Nam prius quam in os iniecta gleba est» (Cicéron, De Legibus, II, XXII, 57). L'humatio, qui correspond donc à l'action d'ensevelir, est un rite incontournable pour consacrer la sépulture. Dans les textes, cette pratique est évoquée de diverses manières, toutes aussi imprécises les unes que les autres, mais qui laissent envisager que seule une partie des os est concernée ${ }^{38}$. Pour ce qui concerne le rite de la crémation, on comprend dans la majorité des cas que ce sont les os calcinés qui sont concernés, mais la notion $\mathrm{d}$ '« os resectum " mentionnée par divers auteurs (notamment Cicéron, Varron, Plutarque, Festus) introduit un doute dans la mesure où nos collègues font intervenir cette pratique avant la crémation (Simon-Hiernard, 1987, p. 93).

Les données archéologiques, qui mettent en évidence des structures diverses, contribuent à poser la question de la nature de la sépulture. Dans un travail récent, nous avons souligné la difficulté que rencontre l'archéologue pour définir les critères d'identification d'une tombe (Blaizot, Tranoy, 2004). Certes, la tombe peut être désignée comme le lieu où est cristallisée la mémoire du mort, ce qui semble en adéquation avec ce que l'on sait des pratiques antiques de commémoration, mais quels moyens archéologiques avonsnous de le reconnaître ? Des bûchers en fosse qui conservent les seuls résidus ou parfois l'ossuaire, aux ossuaires enterrés dans des structures distinctes ou placés hors sol, en passant par les structures creusées expressément pour déposer une part des résidus, que représentent ces structures, quels rites sont-elles supposées illustrer ? En d'autres termes, par quoi se traduit, concrètement, une sépulture dans la société romaine? Par un lieu? Par une structure? Par un ensemble de faits?

38. Parmi les textes réunis par C. Vismara (1991), plusieurs se rapportent à cette pratique.
Si l'on consulte la littérature archéologique ancienne et actuelle, on constate que le bûcher en fosse est invariablement désigné par le terme de bustum, en référence au texte de Festus (De Verborum significationes, 32). Cette appellation est toutefois sujette à caution, puisque l'on peut lui attribuer un sens différent selon les auteurs anciens qui l'emploient. Chez les archéologues, le choix de ce terme n'est en tout cas pas innocent : s'appuyant sur des textes qui lui donnent la dimension d'un lieu de mémoire, l'idée sous-jacente est que le bûcher en fosse est destiné à devenir une tombe, puisque les restes du sujet y sont conservés. En outre, le terme de bustum est parfois employé par certains de nos collègues en opposition avec les bûchers collectifs, qualifiés par celui d'ustrinum, alors que le caractère individuel de ce concept ne transparaît pas spécialement dans les textes antiques ${ }^{39}$.

Les divers exemples que nous avons présentés montrent des situations extrêmement variées (voir chapitres II et III) ; certains bûchers en fosses conservent la totalité du squelette quasi en connexion anatomique alors que d'autres contiennent très peu d'ossements ou ont été totalement vidés, ce dernier cas remettant en question leur nature sépulcrale puisque, a priori, la sépulture est indubitablement liée à la présence des restes du corps. Le caractère strictement individuel du bûcher en fosse n'est, quant à lui, pas validé, dans la mesure où plusieurs bûchers livrent les restes de plus d'un sujet.

Si la grande majorité des bûchers en fosse conservent les restes, peu d'entre eux fournissent une masse osseuse compatible avec celle d'un squelette complet calciné. Un nombre encore moins important renferme, outre des résidus, ce qui, pour nous, désigne indubitablement la volonté de conserver les restes du mort en les mettant en valeur, à savoir l'ossuaire. Toutefois, une autre interrogation concerne les bûchers dépourvus d'ossuaires, dont la couche de résidus fait l'objet d'un réaménagement très spécifique, comme à la Raude, par exemple ou bien, dans un autre style, à Clermont-l'Hérault ou au Mas de Vignoles IX (voir chapitre III) ; est-ce une transformation de la structure primaire en structure secondaire, mais qui concerne cette fois les seuls résidus, ce qui traduirait une forme du rite de l'humatio et donc marquerait quand même le lieu comme sepulcrum?

L'ensemble funéraire de Vernègues, dans les Bouchesdu-Rhône, pose un problème particulier dans la mesure où les bûchers en fosse, en dépit d'un important déficit osseux et de l'absence d'ossuaire, possèdent une couverture et un conduit à libation, les apparentant a priori au lieu

39. La question est développée dans un article rédigé à l'occasion du colloque de Bibracte en 2001 (Blaizot, Tranoy, 2004). 
de mémoire du défunt (Chapon et al., 2004, p. 117-119). Toutefois, l'hypothèse d'un dépôt de surface à côté ou au-dessus de la fosse est suggérée par la découverte au niveau du sol d'un coffre monolithe partiellement détruit jouxtant le bûcher. Cet exemple pourrait indiquer que, dans un certain nombre de cas, nous sommes dans l'impossibilité de reconnaître des bûchers en fosse reconvertis en sépultures, parce que l'un des marqueurs les plus évidents à nos yeux de ces dernières, l'ossuaire, se trouvait en élévation et ne nous est pas parvenu, ou bien parce que le marqueur réel n'est pas l'ossuaire mais la couche de résidus ensevelie. L'hypothèse d'un dispositif pour l'ossuaire en élévation, outre l'exemple du coffre cité ci-dessus, est illustrée dans nos régions par les autels dont le socle renferme les os. Dans la partie occidentale du Sénonais, où les dépôts secondaires de crémation brillent généralement par leur absence, des découvertes de dépôts de mobilier, dont la composition évoque des assemblages cultuels (Séguier, 2006), pourraient s'avérer être les témoins indirects de dispositifs de ce type : seule la partie enterrée subsisterait ${ }^{40}$.

De nombreux bûchers sont caractérisés par la présence d'un ossuaire établi a posteriori, ou bien par des aménagements de surface (couverture, conduit à libation, stèle), démontrant sans ambiguïté qu'ils ont acquis le statut de tombe. Cependant, ces bûchers ne conservent qu'une partie insuffisante de la masse osseuse du squelette, ossuaire compris lorsqu'il existe, ce qui pose un problème si l'on considère qu'il s'agit du lieu de dépôt définitif des restes. Plusieurs hypothèses peuvent être discutées. La première est que le bûcher, établi au-dessus de la fosse, était plus long que cette dernière et que la totalité des résidus ne s'y est pas effondrée ; elle est suggérée par le fait que dans le comblement supérieur des bûchers, constitué d'un sédiment hétérogène mêlant des artefacts d'origines diverses, on retrouve des éléments qui collent avec ceux de la couche de résidus sous-jacente. La deuxième serait qu'une fois l'opération de tri hors fosse achevée, tous les résidus prélevés ne sont pas forcément réintroduits dans le bûcher. La troisième, compatible avec les précédentes, suppose que les restes peuvent connaître différentes destinations, quel que soit le lieu qui représente la tombe. Cette proposition d'un éclatement du lieu de conservation des restes, que nous avions émise en 2001 à propos des dépôts de résidus (Blaizot, Tranoy, 2004), n'a jamais pu être vérifiée dans le contexte d'un ensemble funéraire antique ; elle a été évoquée pour la rue

40. Cette hypothèse impliquerait alors que le passage à l'inhumation généralisée, dans cette région, serait plus tardif que les données actuelles ne le laissent entendre.
Pierre-Audry où des dépôts de résidus furent effectués au pied des tombes monumentales qui renferment l'ossuaire, mais aucun collage n'a été recherché. Nous l'avons testée, pour notre part sans succès, dans l'ensemble funéraire du Replat, à Aime, organisé en enclos, mais aucun dépôt de résidus n'a livré de mobilier recollant avec celui des bûchers situés à proximité. Il en a été de même sur trois séries méridionales étudiées par A. Richier. L'hypothèse a en revanche, et contre toute attente, été démontrée depuis à deux reprises pour le second âge du Fer. En effet, sur les sites de la Cime des Bruyères (Pulvérières, Puy-de-Dôme) et de Bel Air (Saint-Laurent-la-Conche, Loire), deux bûchers en fosse du $\mathrm{II}^{\mathrm{e}}$ s. av. J.-C. contiennent l'ossuaire, tandis qu'une fosse, établie à une certaine distance, livre des ossements et des fragments de mobilier calcinés qui recollent avec ceux du bûcher. La question reste donc ouverte pour l'époque romaine, d'autant plus que cette trilogie : le lieu de transformation du corps (le bûcher), le traitement de ce qui en reste (l'ossuaire) et le traitement des vestiges de la crémation (les résidus), n'est jamais représentée de manière égale dans les ensembles funéraires, certains étant même constitués uniquement de dépôts en ossuaires, ou de résidus, ou encore de bûchers en fosse qui conservent une masse osseuse rarement significative de la totalité des restes d'un individu. Si des sites comme la Favorite semblent indiquer des secteurs différenciés pour la crémation et le dépôt, d'autres, comme celui de l'Ilôt Mas, montrent que les dépôts de résidus peuvent se trouver à distance des dépôts en ossuaire. Doit-on envisager que le caractère quasi monospécifique de certains sites ne reflète que les limites de nos surfaces d'investigations ou le degré de conservation des sites ? Sur la base de la trilogie précitée (lieu de crémation, rite de l'humatio avec l'enfouissement d'une pars pro toto du bûcher et constitution d'un ossuaire), cette hypothèse implique plusieurs propositions théoriques, fondées sur le postulat selon lequel le dépôt en ossuaire et le dépôt de résidus diffèrent dans leur fonction. Dans la première proposition, le déficit en masse osseuse dans les bûchers pourvus d'un ossuaire implique que les résidus peuvent être extraits du bûcher pour être enfouis dans un autre lieu, même si l'on y installe l'ossuaire qui va cristalliser les rites de la mémoire. Dans les cas où l'on ne dispose que des ossuaires, une autre proposition est d'envisager que les bûchers, dont les résidus laissés en place traduiraient le rite de l'enfouissement, se trouvaient à distance des dépôts en ossuaire ${ }^{41}$. Par ailleurs, les quelques esquilles dispersées

41. À En Chaplix à Avenches, des fosses contenant des résidus de crémation se trouvent dans le voisinage des monuments qui renferment les ossuaires (Castella, Flutsch, 1990). 
recueillies dans certains loculi (rues Rochette et Chevrier, à Lyon ; le Pâtural, à Gerzat), témoigneraient d'une modalité différente de l'humatio, susceptible d'échapper à l'attention lors d'une fouille rapide du comblement. Enfin, lorsque l'on n'a que les bûchers ou les fosses de résidus, on peut supposer que les ossuaires, associés à l'une ou l'autre de ces structures, se trouvaient à l'origine au niveau ou au-dessus du sol ou bien dans un autre secteur de l'ensemble funéraire. C'est peut-être en effet le rite de l'humatio qu'illustrent les bûchers directement couverts de terre ou dans lesquels la couche de crémation a été réagencée, alors que d'autres possèdent une couverture. Dans cette dernière situation, où le bûcher est parfois muni d'un conduit à libation, il faudrait envisager que le rite de l'humatio s'exprime par la translation d'une partie des résidus, le reste de la couche de crémation n'étant pas significative, tandis que l'ossuaire est présent, mais que, non placé dans une urne et constitué d'un petit volume d'os, il a échappé à l'identification du fouilleur. Ces propositions cumulées peuvent apparaître comme une façon habile de contourner la complexité d'une masse de données que nous ne parvenons pas à mettre en ordre, dans la mesure où aucune n'est démontrée à ce jour. Elles reposent cependant sur l'évidence d'une dispersion des restes d'un même individu, illustrée par les masses osseuses déficientes relevées dans les différentes structures, que pourrait expliquer l'obligation que revêtent, dans les pratiques funéraires romaines, d'une part l'enfouissement des restes (humatio) et, d'autre part, les rites de commémoration qui devaient être rendus à la mémoire du mort. Une partie des os sélectionnés peut être placée n'importe où, au-dessus du sol, dans une fosse ou dans le bûcher, à l'intérieur ou en dehors de l'espace dévolu au traitement du cadavre, tant qu'une partie des vestiges de la crémation est couverte de terre, d'une manière ou d'une autre, afin que le rite de la sépulture s'accomplisse conformément aux traditions. Ainsi, les textes pourraient se référer aux dépôts de résidus, mais de manière peu explicite.

Un texte de Lucain, du deuxième tiers du $\mathrm{I}^{\mathrm{er}}$ s., rend compte de l'éclatement des restes du mort, puisqu'un soldat promet à son chef de rapporter ses os en Hespérie pour les déposer dans une urne, tandis qu'il en prélève une partie pour les enfouir sur le rivage en marquant l'emplacement par une pierre, afin, précise-t-il, que le tombeau ne soit pas démantelé par ignorance (Lucain, De Bello civili, VIII, 765, 770, 785, 790). Les termes sont clairs : "nautaque ne bustum religato fune moueret », il est bien question d'un tombeau dans cet enfouissement. Un autre texte, écrit au $\mathrm{VI}^{\mathrm{e}} \mathrm{s}$., témoigne également de la dispersion des restes après la crémation (Julius Paulus, Digeste de Justinien, XI, 7, 44) ; il fait état d'ensevelissements en divers endroits (le terme utilisé est « sepultus»), pour dire que l'un et l'autre lieu ne deviennent pas religieux car une sépulture ne peut pas constituer plusieurs sépulcres. Il ajoute également que lorsque les restes sont transférés, le lieu perd son caractère sacré ${ }^{42}$. Ce texte nous informe donc qu'un seul lieu peut exister en droit sacré et que celui-ci est marqué par la présence des restes. Malheureusement, il n'en précise pas les modalités de dépôt. Il convient alors de rappeler un autre texte, évoqué ci-dessus à propos de la notion de bustum, celui de Festus ( II $^{\mathrm{e}} \mathrm{s}$.), qui réunit occasionnellement les deux étapes, la crémation et l'enfouissement, dans une même structure ; l'idée majeure de ce texte reste toutefois de lier indéfectiblement la notion de sépulcre à celle de l'enfouissement («sed modo busta sepulcra appellamus») : le bustum est bien l'endroit où on inhume les restes. La démonstration archéologique au cas par cas du sépulcre reste, on l'aura compris, difficile, c'est la raison pour laquelle nous maintenons notre choix de ne pas employer ce terme pour désigner nos structures, même celles qui nous paraissent les moins équivoques d'entre toutes. Il n'en reste pas moins qu'un certain nombre d'indices, comme ceux évoqués ci-dessus, suggèrent que le bûcher en fosse possède un statut particulier en relation avec la mémoire ; ainsi que le rapporte J. Scheid, une fondation funéraire de Mevania exige que l'on offre, lors des Parentalia annuelles, un banquet " auprès du bûcher » (Scheid, 2005, p. 205). Sur le site de Folly Lane à Saint Albans (RoyaumeUni), c'est sur l'emplacement du bûcher du milieu du $\mathrm{I}^{\mathrm{er}} \mathrm{s}$. que fut construit un fanum à la fin du siècle (Niblett, 2002). Aux 30-32 rue de Bourgogne, à Lyon, les bûchers du $\mathrm{I}^{\mathrm{er}} \mathrm{s}$. sont implantés en bordure de la voie de l'Océan, alors que les structures de dépôt se développent à l'arrière (Schmitt et al., 2007, fig. 198 et supra, chapitre V).

Une autre interrogation, évoquée plus haut, porte sur ce que recouvre exactement l'os resectum. L'absence de situation archéologique claire pouvant se rapporter à ce rite nous conduit à nous interroger sur sa nature, les configurations interprétées comme telles ne nous ayant pas convaincue ${ }^{43}$. La première question concerne le moment où l'os resectum

42. "Cum in diverisis locis sepultum est, uterque quidem locus religiosus non fit, quia una sepultura plura sepulchra efficere non potest: mihi autem videtur illum religiosum esse, ubi quod est principale conditum est, id est caput, cuius imago fit, inde cognoscimur, cum autem impetratur, ut reliquiae transferantur, desinit locus religiosus esse."

43. Trois phalanges en connexion anatomique trouvées « en contexte de crémation ", un pied droit et les métatarsiens d'un gauche en connexion anatomique et non brûlés trouvés sur le fond d'une fosse contenant un dépôt de crémation en ossuaire (Simon-Hiernard, 1987, p. 93) ; une phalange de la main non brûlée, retrouvée dans un sédiment cendreux et charbonneux dépourvu d'ossements calcinés, placé dans un dolium (Grévin, 1997, p. 432). 
est prélevé, les textes n'apparaissant pas très explicites sur ce point. Celui de Festus, par exemple (De Verborum significationes, verset 135), nous informe que l'on coupait un doigt pour lequel on célébrait les cérémonies alors que le corps était brûlé. On comprend là que la cérémonie relative à l'enfouissement de l'os resectum se tient une fois le corps brûlé, mais rien ne dit ici que la pièce osseuse était prélevée avant la crémation. Dans le fameux texte de Cicéron qui évoque la succession des rites funéraires (De Legibus, II, 57, 2, 55), l'inhumation de l'os resectum est également placée juste avant le sacrifice au Lare et après le premier rite au cimetière, puisque, comme le fait remarquer J. Scheid, l'auteur décrit les rites à l'envers (Scheid, 2005, p. 176). En revanche, il ne précise pas non plus à quel moment l'os resectum est retranché. Tout récemment, J. Scheid a proposé de réviser la question en faisant remarquer que les sources les plus fiables, Cicéron et Varron, parlent non pas de membre ou de doigt, mais bien "d'os » (Scheid, 2007, p. 24). L'auteur propose notamment de lire, dans le texte de Varron (De Lingua latina, versets 23 et 25), non pas «os exceptum » mais plutôt « relectum, reiectum ou receptum ", liant ainsi indéfectiblement cette pratique au rite secondaire de l'humatio. Ainsi, dans le cas de la crémation, le prélèvement serait réalisé une fois le corps brûlé et rien ne nous empêche de voir, dans nos dépôts de résidus, l'illustration de cette pratique : la nature ou la quantité de ce prélèvement serait variable, pouvant parfois concerner quelques grammes infimes, équivalent à un doigt, et d'autres fois une part importante, voire la totalité des résidus.

Les configurations archéologiques et les textes nous conduisent à envisager que les dépôts en ossuaire et les dépôts de résidus - qu'ils prennent place dans un bûcher en fosse ou dans des structures distinctes - ne sont pas des variantes d'un même geste, mais l'illustration de gestes différents (Blaizot, Tranoy, 2004). Quelle configuration archéologique désigne la tombe, au sens où nous l'entendons, nous ne pouvons le dire. La notion de sépulture telle qu'elle a été définie de manière générale par J. Leclerc nous paraît applicable à l'Antiquité : il s'agit du « lieu des gestes funéraires ", et plus précisément du lieu où se sont accomplis les gestes ou une partie des gestes liés à la séparation effective, et celui où des gestes s'accomplissent régulièrement en mémoire du défunt (Leclerc, 1996). Toutefois, il semblerait que, dans le cas qui nous occupe, ces lieux peuvent être réunis dans une même structure ou bien constituer des structures différentes. Une chose est certaine, l'ossuaire est l'unité qui fait l'objet des rites de commémoration et donc qui représente le mort, mais pas forcément celle qui consacre la sépulture. C'est pourquoi on peut envisager l'hypothèse suivante : l'idée de sépulture se rapporte plutôt à un ensemble d'actions, réunies ou non dans un même lieu, et dont la plus importante est celle de l'enfouissement. Le moment où J. Scheid propose de placer le sacrifice de la truie, dont les restes sont partagés entre les trois intervenants (Scheid, 2005, p. 173), destiné à purifier la famille et à consacrer la sépulture, est à ce titre emblématique : ce sacrifice, effectué avant la crémation, participe déjà à la finalité de la cérémonie, c'est-à-dire à la constitution de la tombe à venir.

À ce jour, nous pouvons dire que les avancées les plus importantes portent plus sur le renouvellement des questionnements que sur les réponses elles-mêmes. Il en ressort qu'une plus grande attention doit être portée à l'organisation des vestiges in situ et à leur analyse, de manière à pouvoir appréhender et caractériser, au cas par cas, le rôle de ces différentes structures dans les pratiques funéraires. L'inconnue majeure reste la représentativité de nos documents dans les divers cas de figure, qui ne nous permet pas de préciser si une partie de la variabilité que nous percevons, notamment celle de la part prise par tel ou tel type de structure, est un problème de survie archéologique des vestiges ou se rapporte à la réalité. L'image actuelle est que certains bûchers en fosse sont, au même titre que les bûchers de surface, simplement des lieux de transformation du corps, tandis que d'autres constituent le lieu d'ensevelissement, voire celui de la conservation définitive des restes qui vont servir aux cultes liés à la mémoire du mort. Les restes d'un même sujet peuvent avoir connu différentes destinations, l'essentiel étant qu'une partie soit effectivement inhumée et qu'il existe une autre partie dévolue aux cérémonies de commémoration. Tout le problème pour nous est d'identifier la sépulture stricto sensu, car si le sens général que nous accordons à ce concept n'est probablement pas très éloigné de celui de la société antique, la manière dont les vivants percevaient les différentes structures et les relations qu'ils entretenaient, sur la durée, avec chacune d'entre elles, restent difficiles à appréhender. Pour ce qui concerne ces relations dans le temps, on peut s'étonner qu'après avoir scrupuleusement sacrifié à tous les engagements envers le mort et les dieux, dont la constitution de la sépulture n'est pas le moindre, certaines structures, notamment les grands bûchers en fosse, fassent l'objet de superpositions voire de destructions partielles sous la pression du flux de l'occupation des espaces funéraires, par exemple en contexte périurbain. Il appert cependant qu'il en advient de même des grands monuments : quartier du Trion à Lyon, Nîmes, la Grande Borne à Clermont-Ferrand, 
Avenches, etc. C'est bien que l'accomplissement des rites prime sur la survie du lieu, qui dure ce que dure la mémoire effective de ceux qui ont connu le défunt et se sentent engagés par des devoirs envers lui.

\section{LES ÉTAPES DU RITE FUNÉRAIRE TRANSCRITES PAR LES DONNÉES ARCHÉOLOGIQUES}

\section{TEXTES ET DONNÉES ARCHÉOLOGIQUES : DES DONNÉES FRAGMENTAIRES}

Les données archéologiques transcrivent un fonctionnement en plusieurs phases ; l'explication que nous en proposons, c'est-à-dire l'interprétation de ce que nous en avons compris, ne peut s'affranchir du contexte religieux et social connu par d'autres sources, même si nous sommes consciente du caractère accidentel de cette dépendance. Il ne s'agit pas là, toutefois, de tenter d'inscrire à tout prix les informations issues de l'un ou de l'autre système de référence dans une perspective unique, et encore moins d'infléchir la description et l'ordonnance des réalités archéologiques en fonction des textes. Les premières mettent en évidence des lambeaux de gestes rituels, les seconds fournissent le cadre des références générales qui nous sont parvenues de la société et sont soumis également à des présupposés et à des interprétations fondées, elles aussi, sur notre capacité à en ordonner les indices.

Les faits archéologiques peuvent être classés en trois catégories, dont les deux premières au moins sont en relation chronologique indiscutable.

La première concerne le traitement du corps et les rites qui sont liés à cette étape. Ce traitement est marqué par le bûcher, dans le cas de la crémation, et par la fosse sépulcrale, dans le cas de l'inhumation. Elle ouvre la phase de démarcation entre le défunt et le monde des vivants, dans le sens où le cadavre va être séparé de manière effective, physiquement, de ces derniers, par la destruction de son corps (crémation) ou son enfouissement dans la fosse (inhumation).

La deuxième correspond à la constitution de la structure définitive des restes qui, dans le cadre de la crémation, peut être éclatée et qui, dans celui de l'inhumation, est de fait systématiquement confondue avec l'étape précédente. Elle installe le mort dans son nouveau statut, puisque, dès lors, il ne fait plus partie du monde des vivants.

La troisième se rapporte à ce qui pour l'archéologue pourrait être qualifié de «structures accessoires » ou « satellites » dans le sens où elles fonctionnent parallèlement aux précédentes, à divers moments des funérailles et au-delà de celles-ci ; en réalité, elles ne sont que d'autres éléments d'un dispositif unique.

Les deux premières étapes ont un début et une fin et fonctionnent probablement puisque l'on est dans un cadre très ritualiste, traditionaliste, au moyen de plusieurs séquences hiérarchisées, marquées par des gestes précis dont il est légitime d'envisager que les vestiges archéologiques puissent conserver certaines expressions. Nous avons précédemment abordé la question sous l'angle des restes humains, dans l'objectif d'estimer le statut des structures archéologiques mises en évidence. Il nous reste maintenant à examiner les instruments du rite, c'est-à-dire discuter la valeur fonctionnelle des objets impliqués dans le déroulement des funérailles, en partant du postulat qu'ils transcrivent une partie des gestes qui ont scandé les séquences des diverses étapes (Blaizot, Bonnet, 2007, p. 223 ; Blaizot et al., 2007).

\section{LE RÔLE DU MOBILIER \\ DANS LES STRUCTURES FUNÉRAIRES}

\section{Le mobilier du banquet}

Nous avons volontairement banni de notre vocabulaire le terme «d'offrandes » pour désigner l'ensemble du mobilier primaire et secondaire issu des structures archéologiques. Pour certains auteurs, son emploi relève même de l'absurdité dans la mesure où, dans la plupart des cas, les objets appartiennent déjà au mort et il est donc impensable d'estimer qu'on les lui offrait (Testart, Brunaux, 2004), sauf bien sûr si l'on envisage qu'ils étaient apportés par les invités, hypothèse pour laquelle nous n'avons aucun argument. Pour les contextes qui nous occupent ici, on peut considérer toutefois qu'une part du mobilier impliqué en théorie dans les funérailles peut être qualifiée « d'offrande », comme celle qui concerne Cérès sur le bûcher ou les Mânes du mort dans la structure de conservation des restes. Cependant, dans la mesure où ces éléments ne constituent qu'une partie de l'appareil général et que nous sommes incapable d'identifier a priori ce qui correspond à ces pratiques au sein des vestiges, nous nous en tiendrons au terme générique de " mobilier » en précisant qu’il n'est pas employé dans le sens d'une relation univoque au mort. Le terme de munus, parfois employé (Van Andringa, Lepetz, 2006, p. 1132), place une fois de plus ces gestes dans la sphère religieuse ; il s'agit de « dons », de « faveurs » vécues comme un honneur consenti ou reçu, et surtout de s'acquitter de ses devoirs : «Cineri haec mittite nostro munera » (Virgile, L'Énéide, IV, 624). 
Tenter de distinguer, dans le mobilier, les différentes fonctions des catégories d'objets est hasardeux, d'autant que nos données font état d'une grande variabilité de situations. Nous raisonnons dans un premier temps à partir des arguments positifs (présence des objets comme témoins du rite) qui illustrent des situations systématiques.

Fréquemment considérée par les archéologues comme simple conteneur de nourriture pour une vie éternelle (viatique) pourtant bien éloignée des préoccupations de la religion romaine (Scheid, 1984, p. 139), ou comme faisant partie des objets accumulés en tant que tels (« offrandes » d'une coupelle, d'une cruche, d'une lampe...), la vaisselle s'avère être en réalité un véritable acteur de la cérémonie funéraire.

Nous avons vu que les vases issus du bûcher se caractérisaient par la suprématie des vases à nourriture. Nous envisageons donc que cette vaisselle reçoit le repas du défunt dans le cadre du banquet-sacrifice partagé entre le défunt, la famille réunie sur le lieu de la crémation et les dieux, dont les sources littéraires et épigraphiques font grand cas (Scheid, 1984, p. 131 et 2005, p. 167). Comme nous en informe un texte de Catulle (Scheid, 2005, p. 168, n. 17), le repas du mort est bien pris sur le bûcher, ce qui le dissocie clairement de celui des vivants, pris quant à lui sur une table selon un texte d'Apulée, de manière à le soustraire aux divinités infernales (Scheid, 1984, p. 131). Les quelques études réalisées des restes végétaux montrent la présence d'espèces selon toute apparence sélectionnées, puisque l'on rencontre toujours les mêmes quelle que soit la région : fèves, orge, lentilles et vesces en particulier, ainsi que des bouillies de céréales dont de nombreux exemples ont été relevés en Auvergne et en Rhône-Alpes ${ }^{44}$. On note qu'au moins les fèves, les lentilles et les bouillies de céréales sont attestées par les textes relatifs à la cérémonie du culte des morts (feralia; Scheid, 1984, p. 133-134) qui, comme on l'a vu, reproduit les rites des funérailles (Scheid, 2005, p. 181). Le mobilier archéologique recueilli en situation primaire semble donc bien se rapporter au banquet funéraire.

D'autres textes indiquent que les récipients employés par les vivants sont ensuite brûlés (Virgile, Servius) ou détruits (Properce) (Scheid, 1984, p. 131). Ainsi, on peut envisager qu'une partie des vases recueillis dans la couche de crémation des bûchers se rapporte au repas des vivants. Enfin, parmi les récipients calcinés, certains ont probablement contenu les accessoires à la crémation (encens, huiles, parfum, vin), ainsi que le suggère, entre autres, un texte de

44. Études de M. Cabanis (Inrap), L. Bouby et P. Marinval (UMR 8555 du CNRS).
Virgile (L'Énéide, VI, 212-235 dans Scheid, 1984, p. 127-128). Bien entendu, il est difficile de distinguer la part de la vaisselle qui revient à chacune des parties : quelques bûchers, comme ceux de l'Estel dans le Gard ou de Voiron en Isère, montrent des situations qui permettent d'attribuer avec certitude une grande partie de la vaisselle au repas du mort, puisqu'on la retrouve en place sous les restes brûlés du défunt, vraisemblablement installés sur une sorte d'étagère. Par ailleurs, on peut considérer que les cassures rectilignes relevées sur les récipients ouverts, ou les impacts en étoile observés sur les vases fermés, qui ne peuvent pas résulter de l'effondrement du bûcher, ou encore les vases constitués de tessons brûlés à divers degrés, se rapportent vraisemblablement à la vaisselle du repas des vivants, intentionnellement détruite, tout comme aujourd'hui, en Thaillande, les participants à une crémation lancent leurs gobelets en plastique dans les flammes ${ }^{45}$. Cependant, dans la plupart des cas, la conduction du foyer et/ou les réinterventions effectuées a posteriori dans la couche de crémation en vue des prélèvements et parfois du réagencement de cette dernière ont contribué à mélanger l'ensemble du mobilier, ce qui brouille la lecture des faits.

Un autre indice est apporté par la rareté ou l'absence de vases destinés à préparer ou à cuire ; les récipients ne se rapportent qu'à la consommation, les ustensiles de préparation n'étant représentés qu'à l'état de petits fragments, brûlés ou non, dont la situation est de toute évidence résiduelle. Cela nous amène à considérer que les ustensiles de cuisine étaient présents sur les lieux, mais qu'ils jouaient plus un rôle technique que fonctionnel dans le rite. Il est même possible d'envisager que les mets étaient préparés dans l'espace funéraire, ce qu'attesteraient les fours à pain relevés sur les sites de la voie de l'Océan et de la Labre en RhôneAlpes. C'est sans doute ainsi que l'on peut aussi expliquer la part non négligeable, dans les «fosses dépotoirs » de la Favorite, des vases collectifs destinés à la cuisson ou au stockage des liquides, où ils sont associés à des os de faune peu ou non brûlés, relativement à celle que prennent ces récipients dans les résidus de crémation des structures funéraires. Ces «fosses dépotoirs ", comme la fosse fouillée à Saint-Lambert à Fréjus avec ses restes d'amphores et d'os d'animaux non calcinés, conservent probablement une partie de la vaisselle utilisée par les vivants qui, ayant servi aux funérailles, ne peut plus être réinvestie dans l'économie générale et doit donc être détruite.

45. Voir film réalisé par J.-P. Pautreau (UMR 6566 du CNRS, Rennes) dans le cadre de missions ethnoarchéologiques effectuées en Thaïlande du Nord, en mars 1990 et frévrier-mars 1993. 
La seule introduction d'un récipient à usage collectif sur le bûcher est illustrée par une amphore parfois brisée en surface des restes du bûcher après la crémation et dont le rôle se rapporte manifestement à un tout autre registre, sachant en outre que le choix de ce type fonctionnel n'est pas systématique. Toute la cérémonie de cette étape est donc centrée sur la consommation du banquet, sur ce partage ultime qui, paradoxalement, a pour objectif d'engager la séparation entre le défunt et les vivants et donc de purifier ces derniers de la souillure engendrée par la mort. Ce premier banquet ouvre la longue cérémonie des funérailles par laquelle chacun va pouvoir reprendre place dans le monde qui lui revient : son objectif est de restaurer l'ordre des relations sociales, et les rites, une manière de répéter indéfiniment le mythe qui fonde la société en replaçant chaque acteur dans sa communauté.

D'après J. Scheid, la part qui se rapporte à la truie sacrifiée diffère selon qu'elle revient au mort ou aux vivants, de manière à distinguer le premier qui la consomme sous forme de sang (Scheid, 1984, p. 130). Dans les vestiges archéologiques, les os calcinés de porc font vraisemblablement partie des mets généraux, d'autant plus qu'ils se rapportent le plus souvent à plusieurs individus ${ }^{46}$. Là encore, on peut envisager qu'une partie de ces restes illustre les déchets, rejetés dans le bûcher, des pièces consommées par les vivants.

\section{Le mobilier a posteriori}

Pour ce qui concerne la pratique de la crémation, de nombreux exemples développés dans les chapitres III et IV montrent que le mobilier ne joue pas seulement un rôle lors du banquet pris au moment de la crémation, mais qu'il intervient également comme accessoire tout au long des funérailles où, successivement, il est différemment mis en œuvre et en scène.

- Il réapparaît tout d'abord sur le bûcher dès la fin de la crémation : à cette occasion, un vase à liquides (amphore, cruche et éventuellement gobelet) est brisé sur la couche de résidus. Si ce geste semble clôturer la première partie de la cérémonie, on ignore en revanche à quel registre il se rapporte. Symbolise-t-il la séparation d'avec le mort, ou n'est-ce qu'une destruction de l'instrument qui a servi à laver les os prélevés (avec du vin, selon les textes), ou encore illustre-t-il une ultime libation ? Il a été observé dans d'autres contextes de crémation, par exemple dans le tumulus

46. Comme le montre l'étude réalisée par P. Caillat (Inrap) sur le site de la Grande Borne à Clermont-Ferrand. des Athéniens à Marathon ou celui des Macédoniens de Chéronée où il concerne les vases utilisés pour les libations une fois la crémation achevée (Rives-Gal, 1996). Le bris de balsamaires, voire de miroirs, parfois aussi relevé au sommet de la couche de crémation doit-il, dans le même esprit, être associé à un geste de profusiones, ou s'inscritil dans une autre logique, celle d'un honneur aux Mânes pour les parfums et celle d'une symbolique d'inversion pour les miroirs ${ }^{47}$, destinée à marquer la rupture entre la mort (la souillure) et la vie?

- Des vases non brisés sont également placés sur la couche de résidus, parmi lesquels il nous faut distinguer deux situations. La première concerne les dépôts clairement associés aux prélèvements d'ossements dans la mesure où les récipients se trouvent dans la dépression qui correspond au recreusement de la couche de résidus, comme le montrent les exemples du Replat à Aime. La deuxième correspond à des objets (vases, lampes, balsamaires...) que la configuration archéologique ne permet pas de mettre en relation avec le prélèvement dans la mesure où on n'observe pas de recreusement de la couche de crémation, sans doute parce que les modalités de récolte des os ou des résidus ont été différentes. Dans ce cas, nous nous trouvons face à deux interprétations possibles : soit les deux gestes sont bien liés mais les faits archéologiques ne sont pas explicites, soit nous sommes déjà dans le registre du dépôt secondaire, dans l'hypothèse où le bûcher aurait été transformé en sépulture mais où l'ossuaire se trouvait au-dessus du sol. Cette proposition pourrait être particulièrement retenue dans le cas où le dépôt concerne des objets personnels, des outils, de la parure, des instruments de toilette ou encore des restes de nature alimentaire (faune).

- Les modalités de dépôt du mobilier dans les structures secondaires varient tout autant. On retrouve, toujours de manière ponctuelle, la pratique du bris de vase déjà observée en surface de la couche de crémation des bûchers. Si dans ces derniers, le geste parachève la première partie de la cérémonie funéraire, traduit-il, dans les fosses réservées au dépôt définitif des restes, la «consécration » de la structure, l'ouverture ou l'achèvement de la deuxième partie de la cérémonie ou bien encore marque-t-il une sorte de sacrifice consenti à l'égard des Mânes? Il nous faut toutefois préciser qu'il s'agit principalement de vases à liquides ou de balsamaires brisés hors de la structure, puisque seule une partie des récipients est présente, comme s’ils représentaient la pars

47. En Grèce moderne, il est coutume de recouvrir les miroirs de la maison de tissus, noirs de préférence, tant que le défunt n'est pas inhumé. 
pro toto de l'objet impliqué dans cette étape - dont la nature nous échappe - et que l'on voulait prouver, en déposant ces morceaux, que celle-ci avait bien été respectée. Sans doute les fragments de mobilier primaire, parfois réagencés dans la structure de dépôt de manière à les distinguer des résidus stricto sensu, procèdent-ils de la même intention d'attester l'accomplissement du rite (en l'occurrence l'accomplissement du banquet).

- L'autre modalité de dépôt se rapporte aux vases non brisés, uniques ou multiples, qui accompagnent les vestiges calcinés du squelette et, plus rarement, quelques objets personnels. La composition de la vaisselle évoque une fois de plus le repas funéraire (typologie fonctionnelle des récipients, présence occasionnelle d'aliments), mais elle se caractérise par la prévalence des vases à liquides, contrairement à ce qui est observé dans la vaisselle du bûcher où dominent les vases à solides. Cette différence dans la part des fonctions représentées nous conduit à distinguer le rôle de ces deux types de dépôt, primaire et secondaire, dans l'unité des funérailles. C'est pourquoi nous proposons d'interpréter ces dépôts de vases non brûlés et non brisés non pas comme la deuxième partie du banquet funéraire organisé lors de la crémation du corps ${ }^{48}$, ni même comme le rappel qu'il a bien eu lieu, mais comme l'illustration d'un repas distinct de ce dernier, sans doute celui des banquets à venir à l'occasion des fêtes de commémorations. L'hypothèse peut être argumentée par des exemples dans lesquels le mobilier a apparemment été mis en scène, comme si l'on mettait la table : les vases à liquides sont dissociés des vases à solides dans l'organisation spatiale ou dans la chronologie des dépôts, tandis que des dispositifs étagés ont parfois pu être démontrés. Dans ce cadre, la situation dans laquelle se présentent certains objets, retrouvés à l'envers, est difficile à interpréter. Est-elle le résultat d'une situation initiale (surélévation, étagement du mobilier) ou un mode de dépôt réfléchi traduisant le rite de l'inversion?

Les lampes et les rares objets personnels, comme peut-être les balsamaires, ne font, bien entendu, pas partie du registre du banquet. Notons que les lampes sont systématiquement mises à l'écart des autres objets, voire de l'ensemble du dépôt, et que les balsamaires sont fréquemment associés directement aux vestiges osseux. La fonction et le sens de la lampe, qui, en Gaule, constitue un trait bien « romain » du rite funéraire, reste posée (voir infra, p. 334-335).

Les mutilations relevées sur les vases en situation secondaire font partie des observations récurrentes. Dans

48. Contrairement à l'hypothèse que nous avons émise précédemment (Blaizot, Bonnet, 2007, p. 210), alors que nous n'avions pas pris en compte les séries méridionales. l'ensemble des références relatives à cette pratique que nous fournit l'ethnologie (Blaizot, Bonnet, 2007, p. 209) et en l'absence de texte explicite, leur interprétation ne peut être autre que subjective. L'objet mutilé, sacrifié, détruit, perçu comme substitut du corps, ou comme expression de la circulation des biens, ou encore comme symbole du monde des vivants que l'on quitte, sont des concepts qui se rapportent à la notion quasi universelle de rites de passage et qui constituent autant d'hypothèses probables en faveur desquelles nous n'avons toutefois aucune évidence. Peut-on lier ces pratiques à la nécessité d'opposer les morts aux vivants ? Ainsi, en rendant inutilisable la vaisselle du mort, en plaçant une lampe ou en brisant un miroir ou un vase à parfum, les vivants qui, eux, se nourrissent réellement, évoluent dans la lumière, dans un monde d'odeurs et de saveurs, se prémunissent de cet environnement de ténèbres, peuplé d'ombres, dépourvu de joie, d'odeurs, de saveurs et d'images. Il faut cependant remarquer que les mutilations de récipients affectent ceux dévolus au service des liquides, notamment les cruches, comme si cette pratique avait trait au rite de la boisson, ce qui nous renvoie peut-être tout simplement aux coutumes gauloises.

- La mutilation fréquente des vases ossuaires ne peut en revanche relever du même registre. N'a-t-elle pour objectif que de distinguer ce contenant, dans sa fonction, des éventuels vases à solides qui se réfèrent à la consommation, dans le cadre ou non du banquet, puisque le vase est détourné de son usage quotidien ? Les perforations parfois pratiquées sur la panse de ces vases ossuaires ne peuvent, en revanche, participer de la même volonté, mais relèvent plus probablement d'une nécessité fonctionnelle ; on est tenté, en effet, d'y voir un lien avec le dispositif libatoire, les perforations permettant aux liquides versés sur les os de s'écouler dans le sol. L'hypothèse que ces trous aient servi à suspendre des vases pendant la cérémonie, peut-être lors de la consécration de la tombe quand les honneurs sont rendus aux Mânes, à l'image de ce qui est pratiqué en contexte cultuel gaulois (Poux, 2004, p. 287), ne peut être retenue ici en raison de leur emplacement (un sur la panse et un sur le fond, par exemple) et, parfois même, de leur nombre (un seul dans certains cas).

\section{Le mobilier des inhumations}

Pour la période romaine, dépourvue de sépulture à inhumation secondaire, la différence principale entre la pratique de la crémation et celle de l'inhumation est que, dans la seconde, le traitement du corps et l'enfouissement 
sont réunis dans une seule étape et une même structure. Du fait de la gestion du mort en deux temps (le corps puis ses vestiges), la crémation implique un appareil général plus lourd que l'inhumation et une mise en système plus complexe de ce dernier, puisqu'elle permet de décliner les phases du rituel en une infinité de gestes et sous-entend une durée plus importante de cette partie des funérailles qui a rapport au corps. Pour la période romaine, pour laquelle on a eu tendance à opposer fondamentalement ces deux modes de traitement, la question est de savoir si les pratiques relevées dans chacun des cas diffèrent en nature ou seulement dans leurs modes d'expression.

La première difficulté est que les inhumations du HautEmpire renferment généralement peu ou pas de mobilier, contrairement aux bûchers funéraires, dont les vestiges (bûchers en fosse ou dépôt secondaire de résidus) renferment systématiquement de la vaisselle, ne serait-ce qu'un vase ou deux. Aucune des structures examinées dans le cadre de ce dossier n'en est en effet dépourvue, ce qui signifie qu'opter pour l'inhumation semble correspondre au choix d'une mise en scène moins ostentatoire de ses funérailles.

Mais que représente ce mobilier, en regard de celui qui intervient dans les différentes étapes de la crémation?

Globalement, la composition et l'organisation des dépôts évoquent là encore le repas. Le plus souvent, comme sur le bûcher et dans les dépôts de crémation, les pièces ne semblent pas disposées au hasard. Les vases s'avèrent principalement placés au niveau de la moitié inférieure du corps, mais, lorsqu'ils sont répartis en plusieurs endroits de la tombe, ils sont généralement séparés par types fonctionnels (vases à liquides préférentiels au niveau de la moitié supérieure du corps par exemple ou, pour le Bas-Empire, sur le sol d'inhumation plutôt que sur le couvercle ou une étagère). Certains ont de toute évidence été disposés sur un présentoir étagé, avec les vases à liquides placés en haut dans les inhumations du Haut-Empire, les pots sur le couvercle du cercueil et les coupes et les plats sur des étagères au BasEmpire. Cette organisation revient en quelque sorte à dresser la table, comme nous l'avons suggéré pour les structures qui se rapportent à la crémation. On remarque que tout au long de l'Antiquité, les vases à liquides sont dissociés des vases à solides dans les structures funéraires ; c'est déjà le cas à l'âge du Fer, situation que M. Poux lie au caractère non alimentaire du vin (Poux, 2004, p. 284) et que nous avons attribuée à la distinction entre les deux parties du banquet, la seconde étant consacrée à la boisson (Blaizot, Bonnet, 2007).

L'analyse fonctionnelle des vases (voir chapitres I et IV) laisse envisager une parenté entre le mobilier des inhuma- tions et le mobilier secondaire des structures de dépôt de crémation. Considérons, d'un côté, la part importante des vases à liquides et leur fréquente mutilation, et, d'un autre côté, le comportement parallèle dans ce qui a trait à l'évolution de la pratique (baisse sensible au cours du temps) ; le mobilier des inhumations pourrait ainsi se rapporter aux futurs banquets des commémorations, ce qui signifie que le banquet partagé, illustré par le mobilier primaire des bûchers funéraires, n'est pas représenté dans la tombe. Dans les structures de dépôts de crémation, ce mobilier est toutefois présent dans les résidus, associés de manière certifiée à l'ossuaire dans les structures mixtes et peut-être plus largement si l'on considère que ces derniers pouvaient être placés au-dessus du sol. Doit-on alors envisager que dans les inhumations, les deux banquets sont réunis en une seule fois, mais que le faible nombre de vases ne permet pas forcément de le mettre en évidence ? L'hypothèse peut être discutée dès lors que l'on examine les sépultures pour lesquelles la mise en scène du mobilier, illustrée par des dépôts de vases complets et de vases incomplets, s'avère complexe. En effet, les récipients complets et les récipients incomplets, jetés dans la fosse sous le corps ou sur le couvercle du contenant (plus rarement à l'intérieur de ce dernier) ne sont généralement pas représentés par les mêmes fonctions. Si les liquides et les solides sont représentés dans les vases complets, les vases brisés (souvent à l'extérieur de la tombe), dont des fragments sont rejetés dans les fosses, appartiennent à la catégorie des vases à solides, tandis que les vases brisés sur le fond de structures (sous le corps) sont essentiellement des vases à parfum ou à liquides. Cette caractéristique, relevée dans les dépôts de crémation, suggère deux conclusions. La première est que les deux pratiques de bris (avant et après le dépôt du corps) ne se rapportent sans doute pas au même registre du rituel. La seconde est que les vases brisés hors de la tombe pourraient faire référence au premier repas partagé, dont on trouve l'équivalent sur le bûcher. Ces tessons représenteraient alors la pars pro toto de ce banquet, peut-être celle des vivants, attestant par cela qu'il a eu lieu. De toute évidence, l'illustration de cette étape, comme celle d'ailleurs du banquet de commémoration, est loin d'être systématique sur l'ensemble des séries. La lecture des sépultures pourvues d'un vase unique, par exemple, est difficile : ce vase illustret-il, de même, la pars pro toto du banquet?

Comme dans les structures de dépôts de crémation, l'interprétation des objets retrouvés à l'envers sur le fond des fosses reste délicate (effondrement ou référence au rite de l'inversion). À noter enfin qu'à l'instar de ce qui est 
observé dans les dépôts de crémation, les vases mutilés sont ceux destinés à la consommation des liquides.

Au final, grâce aux séries de sépultures dans lesquelles l'intégralité de l'appareil funéraire et de sa mise en scène est exprimée, on peut dire que les différences de traitement du corps (brûlé ou inhumé) n'impliquent pas une différence de rites. Cependant, le fait d'illustrer les étapes du rituel dans les structures se révèle moins courant dans la pratique de l'inhumation que dans celle de la crémation, les instruments du rite étant rarement intégralement déposés dans la tombe, voire pas du tout. Pour ce qui concerne la crémation, le banquet partagé est systématiquement représenté sur le bûcher, tandis que celui qui est évoqué par le mobilier secondaire non brûlé est moins fréquent.

\section{LA PLACE DES STRUCTURES ET DES DISPOSITIFS LIÉS AUX SACRIFICES ET AUX LIBATIONS}

D'après les textes, deux fêtes commémorent les défunts (Scheid, 2005, p. 178). L’une, qui dure une journée (parentatio), se rapporte à une date d'anniversaire (celle du décès, de la naissance) et se résume à un holocauste offert aux Mânes. L'autre, qui se tenait tous les ans en février (Parentalia), comprenait des sacrifices funéraires, les parentationes, composés de deux unités distinctes : un holocauste et un banquet. Ces sacrifices reproduisent non pas la partie des funérailles qui se rapporte au traitement du corps ou de ses restes, mais celle de la neuvaine au cours de laquelle on sacrifie aux Mânes (holocauste) et au Lare (sacrificebanquet), puisque l'on respecte le délai des huit jours après le début des festivités. Malheureusement, les textes relatifs au déroulement de ce rite sont peu explicites sur le contenu du sacrifice et du repas.

Hormis les attestations de conduits à libation, les pratiques liées à la commémoration ont très rarement été mises en évidence en Gaule en raison de la fréquente érosion des sols. Nous n'avons guère pu citer que les exemples des coupelles à deux anses de Lyon ou des petits vases de la villa de Banassac, écrasés à la surface du sol, ou encore ceux du Valladas retrouvés au-dessus des dépôts (voir chapitre IV). Au-dessus de l'une des tombes de Banassac, les petits récipients ont manifestement été déposés sur la durée, puisqu'un tertre est constitué de plusieurs séquences successives, caractérisées par des apports de terre sur des couches de récipients brisés (Feugère, Gros, 1996, p. 292).

La question de l'étape à laquelle interviennent les libations sur les tombes a été discutée plus haut en raison de la situation des vases ossuaires, certains étant de toute évidence enfermés dans une boîte, alors qu'ils sont munis d'un couvercle percé destiné à introduire un conduit à libation. Nous nous trouvons devant deux possibilités : soit la fosse était réouverte pour pratiquer la libation, soit cette dernière avait lieu une seule fois au moment de l'enfouissement. La première hypothèse s'avère plus probable à la lumière des données archéologiques : des vases ossuaires possèdent un bouchon amovible (exemple du dépôt exhumé sur le site de l'Ilôt Mas à Lyon), parfois sous forme d'un galet, et, dans plusieurs cas, les fosses qui contiennent l'ossuaire présentent les indices d'un colmatage différé, indiquant que le dépôt était accessible. On peut également se référer aux dispositifs attestés dans les autels de la rue Pierre-Audry à Lyon : un côté de la base est muni d'une « porte » qui communique avec un orifice permettant l'accès d'un conduit à l'ossuaire.

Les conduits à libation relevés dans les bûchers en fosse se rapportent-ils au même registre que ceux associés aux ossuaires dans les structures secondaires ? La question est posée dans la mesure où on les rencontre moins dans les bûchers où un ossuaire a été mis en évidence (seulement deux cas certifiés sur neuf avec conduits à libations avérés) que dans ceux dont la couche de résidus est réagencée (sept cas certifiés sur neuf avérés). Si les proportions sont faussées en raison de l'arasement de la plupart des structures (ayant détruit conduits et ossuaires aériens éventuels) et de la disparition de probables dispositifs à libation en matériau organique, cette association des résidus et des conduits au sein des bûchers, non relevée dans les structures de dépôt, est surprenante, à condition qu'il ne s'agisse pas d'un artefact de conservation.

Nos contextes archéologiques livrent des assemblages et des structures qui se rapportent sans aucun doute à des rites de sacrifice. C'est le cas des « fosses rituelles » qui comportent des céramiques de petite taille et des restes alimentaires calcinés. Nous pourrions les associer aux holocaustes dédiés aux Mânes, du fait de l'absence d'ossements humains, de la non-fonctionnalité des vases mis en ouvre (trop petits pour avoir servi lors d'un repas) et de la calcination poussée de l'ensemble, rendant improbable la consommation effective des denrées en présence. En effet, comme le précise J. Scheid, les victimes présentées aux divinités d'en bas étaient complètement brûlées parce que les vivants ne pouvaient se mettre à table avec les divinités qui patronnaient le monde des morts (Scheid, 1998, p. 79). Le sacrifice des Parentalia s'opère au moyen d'un bûcher construit par terre et les victimes ne sont pas partagées avec les vivants : il marque la séparation définitive d'avec le mort (Scheid, 
2005, p. 205). Dans nos exemples régionaux comme sur le site des Sagnes, les contextes dont proviennent ces fosses, dépourvus d'inhumations, indiquent que ces fosses n'ont pu être pratiquées qu'à partir de la deuxième étape des funérailles (la neuvaine), puisqu'au moment de la crémation du corps, le sacrifice ne s'adresse pas aux Mânes. Toutefois, dans la mesure où les rites de commémoration répètent en partie (Parentatio) ou en totalité (Parentalia) ceux de la neuvaine ou, en tout cas, que les textes ne fournissent pas les éléments nécessaires pour distinguer archéologiquement ces trois rites, nous manquons d'indices pour déterminer la place de nos données au sein des pratiques funéraires.

Le site des Quaires, contrairement à celui de la Grande Borne, nous conduit à poser l'hypothèse d'une simultanéité de ces pratiques et de l'inhumation des restes calcinés du défunt. En effet, des liaisons secondaires par collages ont pu être établies entre des céramiques provenant à la fois de «fosses rituelles » et de structures secondaires de crémation. Par ailleurs, de rares esquilles osseuses humaines ont été relevées dans deux fosses, une à la Grande Borne (un fragment) et l'autre aux Quaires (six fragments). Ces exemples constituent-ils un élément suffisant pour envisager que ces fosses participent à la cérémonie de l'enfouissement et ne sont pas liées à la commémoration ? Cependant, si c'est le cas, cela signifierait que l'on attend la fête de la neuvaine pour enfouir le mort ou au moins pour pratiquer l'humatio. Or, de très rares exemples contredisent la proposition d'un dépôt différé ; à Aime, les os d'une inhumation recoupée par la fosse d'un dépôt de résidus présentent des traces nettes de brûlures à l'état sec (os noirs à gris mat avec des rétractions longitudinales) qui résultent de toute évidence de leur contact avec les résidus. Le même phénomène est relevé sur le site de la Vigne de Bioaux à Valros (Hérault). Dans ces deux cas, les résidus ont de toute évidence été déposés alors qu'ils étaient encore incandescents, ce qui indique que la crémation et la structure secondaire se sont succédé sur un laps de temps inférieur à 18 -20 heures ${ }^{49}$. Les liaisons secondaires relevées aux Quaires pourraient tout aussi bien résulter d'une certaine proximité des structures ou des espaces dans lesquels ces différentes activités ont été réalisées. Dans ce cas, les éléments de mobilier provenant des bûchers se seraient retrouvés de manière accidentelle dans ces fosses. Cette hypothèse nous semble recevable dans la mesure où la part des tessons se rapportant au mobilier primaire des crémations y est très faible (un à

49. Sur le bûcher expérimental d'Acy-Romance, la température des dernières braises atteignanit encore $680^{\circ} 16 \mathrm{~h} 30$ après l'allumage (Lambot, 1994, p. 260-261). cinq tessons dans chacune des fosses) et où dans une même " fosse rituelle », les tessons en question se rapportent à des récipients issus de plusieurs structures de crémation. Par ailleurs, les niveaux de sol de la Porte Nocera à Pompéi livrent de nombreux fragments de fruits, de graines et de pain carbonisés, associant ces éléments à des rites de surface (Lepetz, Van Andringa, 2006).

Les vestiges de ce rite sont rares, tant dans nos régions que dans celles où ils ont ponctuellement été relevés (voir chapitre IV). Sans doute faut-il attribuer ces lacunes documentaires à des modalités différentes de destination des restes (enfouis ou laissés en surface). La question, qui vaut également pour ce qui concerne la part du repas funéraire dévolue au défunt, a priori consommée sous forme de fumet comme celle des dieux (Scheid, 2005, p. 185), est posée jusque dans l'Antiquité tardive pour la pratique de l'inhumation, puisque mis à part trois cas sur le site de la Brèche à Laudun (voir chapitre I), on ne connaît aucun foyer ayant livré des vestiges alimentaires calcinés ${ }^{50}$ pouvant clairement être associés à une inhumation. Sur le site de la Brèche, les restes du foyer ont été déversés dans le comblement des fosses ; si on l'envisage de manière générale, l'absence de ces vestiges en place doit être mise sur le compte de la taphonomie.

\section{LA DIVERSITÉ ARCHÉOLOGIQUE : VARIABILITÉ DES RITES OU VARIABILITÉ DES PRATIQUES ?}

La variabilité des modèles est illustrée dans divers registres.

D'abord, dans le traitement du corps qui peut être brûlé ou inhumé à l'état de cadavre, ces modalités variant selon les époques et les lieux. Cette coexistence est mentionnée dans les textes, mais n'est jamais accompagnée d'une remarque relative aux rites spécifiques que le choix de l'une ou de l'autre pourrait éventuellement déterminer. L'analyse développée ci-dessus montre d'ailleurs qu'il n'en est rien, le mode de traitement du corps apparaissant comme une variable parmi d'autres, ce que confirme, en l'occurrence, l'ampleur des variations relevées, qu'il s'agisse d'inhumation ou de crémation.

Ensuite, la variabilité s'exerce, comme nous l'avons vu, sur la forme que prennent les structures de dépôt de crémation : réutilisation de la structure de combustion pour le dépôt de résidus (réagencement) et/ou pour l'ossuaire, séparation spatiale de l'ossuaire et des résidus (deux fosses distinctes ou, probablement, situation aérienne de

50. Ceux du Patis ou de Pommerol n'en contiennent pas. 
l'ossuaire) ou réunion des deux unités dans une même fosse tout en les distinguant (à l'aide d'une paroi, d'une couverture par le dépôt du vase ossuaire dans une boîte). Si notre lecture des faits est acceptable, il ne s'agit là que des variantes d'un dispositif identique dans sa conception générale, puisque les pratiques restent les mêmes.

La variabilité est extrême pour ce qui concerne la quantité d'ossements ramassés sur le bûcher pour constituer les dépôts. Celle-ci peut être constituée de quelques grammes ou de la quasi-totalité du squelette.

Le mobilier placé sur le bûcher varie en nombre mais peu en nature.

Le mobilier secondaire recueilli dans les bûchers ou dans les fosses de dépôt varie en revanche beaucoup plus en nature et en nombre que le mobilier primaire. En outre, il varie en occurrence, puisque de nombreuses structures primaires ou secondaires de crémation n'en comportent pas.

Le mobilier des inhumations du Haut-Empire ou du BasEmpire varie également en occurrence, en nombre et en nature (vases à liquides, à solides, à parfum, lampes...).

La variabilité touche également la manière dont le mobilier est placé dans les structures de dépôt. Parmi la vaisselle du dépôt secondaire, les récipients expressément brisés, dont il nous reste les fragments rejetés dans la fosse, se rajoutent le plus souvent à ceux qui sont rationnellement disposés, quelle que soit la structure (dépôt de crémation ou inhumation). Le bris des vases à parfum échappe à ce modèle, sachant qu'un flacon brisé peut être l'unique vase recueilli dans la structure. Ces deux pratiques sont en tout cas loin d'être rencontrées dans toutes les structures. Dans les inhumations, que ce soit au Haut-Empire ou au Bas-Empire, l'emplacement des vases qui ont fait l'objet d'une véritable installation est aussi soumis à une importante diversité : on distingue deux grandes tendances ; la première se rapporte à la situation privilégiée des vases au niveau de la moitié inférieure du corps et à la prédominance du service des liquides pour ceux qui sont placés au niveau de la moitié supérieure. La seconde se réfère au traitement (bris, mutilations) et à la répartition spatiale (étagement des vases par exemple) différentiels selon la fonction des récipients, mais nous ne constatons rien d'exclusif, même au sein d'une seule série. Les faits sont semblables pour ce qui concerne la relation entre les catégories fonctionnelles des vases du mobilier secondaire et l'ossuaire : très fréquemment, les vases à liquides sont au contact du vase ossuaire, tandis que les pots en sont séparés par un dispositif, mais il existe des contre-exemples. Les vases à parfum sont souvent au contact voire à l'intérieur de l'ossuaire.
Les mutilations de vases ne sont pas non plus systématiques, tant dans les structures qui se rapportent à la crémation que dans celles qui concernent l'inhumation.

L'ensemble des manifestations de cette variabilité se retrouve dans toutes les régions examinées dans ce dossier et au sein de toutes les séquences chronologiques, même si certains paramètres sont soumis à une évolution dans le temps. Que signifie cette variabilité ? Est-elle initiale ou résulte-t-elle d'un biais archéologique ? Notre difficulté à sélectionner des structures pour lesquelles on dispose de renseignements relatifs à tous les registres, en raison de l'érosion des sites et parfois d'un enregistrement insuffisant des faits, augmente probablement notre variabilité archéologique. Celle-ci procède-t-elle d'une lecture erronée des faits, qui accorde un sens à ce qui n'en a pas, dans la perspective qui est la nôtre ? Ou bien faut-il plutôt envisager qu'une partie de la population n'effectuait pas tous les gestes des rites, voire qu'elle n'accomplissait pas les rites funèbres? Ces hypothèses semblent improbables dans le contexte ritualiste qui est celui de la société romaine. On se retrouve devant la même énigme que nos collègues qui travaillent sur le monde grec, également caractérisé par une extrême variabilité des pratiques funéraires dans l'espace et dans le temps (Polignac, 2005, p. 175). Or, comme le fait remarquer l'auteur, on ne peut pour autant renoncer à donner un sens à ces pratiques en les qualifiant d'arbitraires, et il convient plutôt de les considérer comme des «stratégies actives de communication par lesquelles les groupes se définissent les uns par rapport aux autres » (id., ibid., p. 180).

C'est dans cet esprit que l'on proposera qu'au sein d'une communauté définie dans le temps et l'espace, la variabilité ne reflète probablement rien d'autre que des mises en scènes différentes du rite, des initiatives " personnelles ». Celles-ci sont peut-être définies en fonction de la dimension collective que revêt le décès de la personne et de la mesure ostentatoire que la famille entend accorder aux funérailles, ou bien selon des traditions familiales qui vont primer sur le jeu social. Les funérailles romaines étant une affaire familiale, célébrées non pas par le filtre d'une institution, mais par celui qui détient l'autorité dans la famille, toute cette variabilité ne fait sans doute que traduire la différence entre la norme et les coutumes. Rappelons également ce que nous avons défini dans les prolégomènes de ce chapitre et que nous développerons plus bas, à savoir que les pratiques funéraires ont un rôle social affiché, dans le sens où elles permettent à la famille et donc plus largement à un groupe d'affirmer son identité et son image. 
La diversité des situations rencontrées ne peut donc être interprétée sans distinguer l'accomplissement du devoir du rite (incontournable) et ses modes d'expression (variables). Dans ces derniers, la dévolution des objets du rite et la représentation des actions impliquées pourraient constituer des codes parmi les plus variables. Par exemple, si les objets ne sont pas enfouis, s'ils sont rejetés sur le sol ou enterrés à distance de l'aire sépulcrale avec un ensemble d'autres vestiges liés à plusieurs étapes de la cérémonie, comme on peut le supposer par le contenu des grandes « fosses dépotoirs » des contextes lyonnais, l'archéologie n'est pas en mesure d'identifier les témoins de chacune de ces étapes dans la structure qui rend compte des funérailles. Pour ce qui concerne les symboles des actions, on se référera à la proposition de J. Scheid qui lie le dépôt d'accessoires placés dans la tombe aux représentations du banquet sur les stèles ou les monuments (Scheid, 2005, p. 188) ; avons-nous là deux expressions différentes d'un même message, dont le second est soumis aux aléas taphonomiques ? Au final, il nous faut considérer que l'absence d'un objet ne signifie pas forcément que le geste n'a pas été accompli.

\section{PRATIQUES FUNÉRAIRES ET SOCIÉTÉS}

\section{DE L'ÂGE DU FER AU HAUT-EMPIRE, CONTINUITÉS ET DISCONTINUITÉS DES PRATIQUES FUNÉRAIRES}

Un certain nombre de pratiques relevées dans les contextes présentés ici ne sont pas totalement nouvelles en Gaule. Au contraire, la continuité de nombreuses références avec l'âge du Fer s'avère évidente. Cependant, leur mise en scène, ou les relations que les différentes variables du rite entretiennent entre elles constituent une innovation, ce que nous proposons d'examiner ci-dessous.

\section{CONTINUITÉS FORMELLES DES PRATIQUES}

En dépit du faible nombre de structures relatives à la période située aux alentours de l'ère, les données recueillies pour les $\mathrm{II}^{\mathrm{e}}$ s. et I ${ }^{\mathrm{er}} \mathrm{s}$. av. J.-C. permettent de dégager les faits suivants.

Autour du I ${ }^{\mathrm{er}}$ s. apr. J.-C., la crémation domine largement l'ensemble des régions examinées. Pour le midi de la Gaule, elle s'inscrit dans la continuité des pratiques protohistoriques (Dedet, 2004), les inhumations restant à ce jour rarissimes avant le deuxième tiers du I ${ }^{\mathrm{er}}$ s. apr. J.-C. En Auvergne et dans les Alpes du Nord, où l'inhumation et la crémation coexistent avec, semble-t-il, une nette prédilection pour la première, la crémation explose littéralement vers le début de notre ère, et devient majoritaire au I ${ }^{\mathrm{er}}$ s. apr. J.-C. dans cet ensemble géographique.

Pour ce qui concerne les inhumations, les sépultures se présentent de manière identique à La Tène finale et au I $^{\text {er }}$ s. apr. J.-C., tant par la typologie même de la structure que par les modalités de dépôt du corps. Au cours des deux périodes, le dépôt de mobilier reste minoritaire ou limité à un récipient, sauf dans des cas exceptionnels illustrés par des tombes architecturées (chambres coffrées ou fosses couvertes comportant un contenant de bois), où il fait d'ailleurs l'objet d'une mise en scène particulière.

À l'échelle des régions étudiées, les pratiques enregistrées au second âge du Fer dans le cadre de la crémation sont soumises à une certaine variabilité. Le Midi ne livre que des structures de dépôt caractérisées par une faible quantité d'ossements, le plus souvent dispersés, les dépôts mixtes étant plus rarement attestés, surtout en Languedoc (Bel et al., 2008). Le mobilier primaire s'avère exceptionnel et est illustré par des restes alimentaires ou des armes, presque jamais par de la vaisselle, alors que le mobilier secondaire est nombreux. Il se compose de nombreux récipients sélectionnés (Bats, 2002, p. 290) et de dépôts carnés, disposés par fonctions sur des supports étagés (Metzler-Zens et al. dir., 1999, p. 424 ; Poux, 2004, p. 284 ; Bel et al., 2008), tandis que certains sont intentionnellement brisés. En Auvergne, les faits apparaissent plus diversifiés : on rencontre surtout des dépôts de résidus dépourvus de mobilier primaire et secondaire, placés dans de petites fosses, dont la masse osseuse est très variable (de quelques grammes à plusieurs centaines de grammes). Les ossuaires en contenants périssables (site d'Aulnat/Gandaillat, ${ }^{\mathrm{I}}{ }^{\mathrm{e}}$ s. av. J.-C.), les dépôts de résidus pourvus de mobilier primaire sans mobilier secondaire (site du hameau des Peupliers à Rochefort, fin du II $^{\mathrm{e}}$ s.-milieu du I ${ }^{\mathrm{er}}$ s. av. J.-C. ; site du Grand Navarre à Malintrat, II ${ }^{\mathrm{e}}$ s. av. J.-C.) et les ossuaires en contenant céramique avec du mobilier secondaire (sites du Brézet et du Jardin botanique à Clermont-Ferrand, de Lezoux, $\mathrm{I}^{\mathrm{er}}$ s. av. J.-C.) s'avèrent plus rares. Enfin, les bûchers en fosse restent exceptionnels (la Cime des Bruyères à Pulvérières, $\mathrm{II}^{\mathrm{e}}$ s. av. J.-C., et peut-être le hameau des Peupliers). À la Cime des Bruyères, au moins un des bûchers comporte un vase ossuaire, du mobilier secondaire, tandis que deux dépôts de résidus provenant de ce bûcher se trouvent à proximité. La même pratique, qui décline les restes en plusieurs unités distinctes, est relevée sur le site de SaintLaurent-la-Conche, dans la Loire (II ${ }^{\mathrm{e}}$ s. av. J.-C.). 
Globalement, lorsque les structures comportent du mobilier, celui-ci est toujours plus nombreux et varié dans les structures qui se rapportent à la pratique de la crémation que dans les inhumations, aussi bien à l'âge du Fer qu'à l'époque romaine. Quel que soit le mode de traitement du corps choisi, plusieurs vases ou objets sont incomplets ou mutilés. Les objets brisés, les objets intacts ou simplement mutilés connaissent généralement une répartition spatiale différentielle au sein de la structure (Metzler-Zens et al. dir., 1999, p. 388-389 ; Poux, 2004, p. 284 ; Bel et al., 2008 ; données inédites d'Auvergne compilées par F. Blaizot, A. Wittmann et Y. Deberge).

Les pratiques liées à la commémoration sont mal documentées à l'âge du Fer. Les tessons d'amphores recueillis au sommet du colmatage des structures de dépôt languedociennes des $\mathrm{II}^{\mathrm{e}} \mathrm{s}$. et $\mathrm{I}^{\mathrm{er}} \mathrm{s}$. se rapportent-ils à cette pratique (Bel et al., 2008) ? Toute la difficulté ici consiste à évaluer le moment auquel le dépôt a été effectué. Ces éléments, qui proviennent à la fois des niveaux de sol, du comblement des structures ou d'un secteur de la fosse, comme c'est le cas dans les ensembles funéraires de Lamadelaine, de Bonnert et de Feulen, au Luxembourg, ou d'En Chaplix à Avenches en Suisse (Castella et al., 2002, p. 47), sont interprétés comme ayant joué un rôle dans les cérémonies qui précèdent la mise en terre (Metzler-Zens et al. dir., 1999, p. 401-402). M. Poux, en revanche, situe ces dernières bien après l'obturation des sépultures (Poux, 2002a, p. 362), ce qui revient à envisager des rites de commémoration.

Tout repas cultuel comporte un sacrifice, que ce soit à l'âge du Fer (Poux, 2002a, p. 361) ou à l'époque romaine (Scheid, 2005). Certaines tombes du Languedoc-Roussillon associent des os de faune et un couteau, souvent placés sur le fond de la structure, attestant des rites sacrificiels à la fin $d u \mathrm{II}^{\mathrm{e}}$ s. av J.-C. (Bel, à paraître). On n'a en revanche rien de tel en Auvergne, où les rares dépôts de faune ne côtoient aucun couteau dans les tombes à inhumation ${ }^{51}$. Le cas d'une chèvre complète sacrifiée sur le couvercle d'un cercueil monoxyle renfermant une inhumation de La Tène C1-C2 à Aulnat/Gandaillat (SP366) reste, somme toute, peu explicite ; le sens et la dévolution de ce sacrifice sont en effet peu clairs (sacrifice aux dieux ?, hommage au mort ?, purification de la famille ?, simple signe d'ostentation ?). Les résidus de crémation livrent, quant à eux, des vestiges calcinés de faune, mais rien ne prouve que les animaux furent mis à mort selon un protocole sacrificiel. Soulignons

51. Notons que l'inhumation augustéenne de la rue du Mont-d'Or, à Lyon, renferme un couteau placé dans un pot (voir chapitre I, fig. 46, p. 58). qu'il en est de même à l'époque romaine, où le sacrifice de la truie est attestée par les sources écrites et non pas par les données archéologiques ; les restes de porc dans les bûchers ou dans le mobilier secondaire peuvent aussi bien témoigner d'un sacrifice que d'un simple abattage en vue de leur consommation réelle et symbolique. Le sacrifice est-il, dans ces régions pour les deux époques, en grande partie transposé dans les mutilations et destructions - par bris et crémation - de vases ? Dans les sanctuaires laténiens, les amphores brisées, calcinées, aux panses décolletées sont ainsi interprétées comme les substituts ou métaphores de sacrifices (Poux, 2004, p. 339-340).

L'ensemble de ces configurations, observées indépendamment les unes des autres et dans des secteurs géographiques distincts à l'âge du Fer, rappellent celles que nous avons mises en évidence pour l'époque romaine, la différence étant qu'elles apparaissent représentées simultanément sur l'ensemble des secteurs géographiques étudiés. Cette dynamique est marquée par un double courant: d'une part la crémation se généralise autour de l'ère, même dans des régions où elle était minoritaire, et d'autre part l'inhumation devient plus fréquente vers le milieu du $\mathrm{I}^{\mathrm{er}} \mathrm{s}$., dans des secteurs où elle était absente. Certaines pratiques sont même relevées jusque dans l'Antiquité tardive, notamment celles qui concernent les gestes liés au dépôt de mobilier (choix fonctionnels, traitement des vases, modalités de dépôt). Par rapport à l'âge du Fer, si l'on s'en tient à ces grandes lignes, l'ensemble des pratiques funéraires de l'époque gallo-romaine donne l'impression d'une plus grande «homogénéité » ou plutôt d'un lissage général.

\section{DISCONTINUITÉS FONDAMENTALES}

Si des continuités formelles sont observées dans les pratiques funéraires de La Tène finale et du Haut-Empire, des différences méritent toutefois d'être soulignées.

Parmi les plus flagrantes, la part accordée à la crémation elle-même, c'est-à-dire à l'étape du bûcher, apparaît beaucoup plus importante à l'époque romaine que sur nos sites de l'âge du Fer. En témoignent tout d'abord l'inflation de la pratique dans l'ensemble de la Gaule et l'abondance et la fréquence du mobilier primaire ; en contrepartie, le mobilier secondaire s'avère non seulement moins systématique, mais aussi moins abondant et diversifié que le premier. Cette remarque a deux implications.

La première est que, mis à part les cas des funérailles " aristocratiques ", la structure de dépôt est la seule qui fixe le statut du mort et l'ensemble des rites funéraires du 
second âge du Fer ; la seconde est que le mobilier secondaire n'a probablement pas la même fonction aux deux époques. Les études réalisées sur les ensembles funéraires protohistoriques s'accordent pour interpréter le mobilier secondaire comme vestige du repas funéraire partagé entre les vivants et le mort (Bats, 2002, p. 287 ; Bel, à paraître) ou, en tout cas, posent la question du banquet dans ces contextes (Mazière, 2002 ; Poux, 2004, p. 326). On peut proposer l'hypothèse selon laquelle le mobilier secondaire du second âge du Fer illustrerait bien le banquet des funérailles consommé par les vivants et les morts, mais que celui placé dans les structures de dépôt à l'époque romaine, s'il ne symbolise pas le sacrifice aux Lares (dont le partage avec le défunt n'est pas certifié), correspondrait plutôt aux repas sacrificiels à venir des rites de commémoration. Quoi qu'il en soit, il faut envisager que le système romain possède un sacrifice-banquet de plus qu'au second âge du Fer, et que les deux banquets (l'un partagé avec le mort, et l'autre qui relève de la seconde partie des funérailles ou bien des rites commémoratifs) peuvent être dissociés, puisque le premier, calciné, est représenté dans le dépôt de résidus et le second, non brûlé, se trouve avec l'unité qui se rapporte explicitement au défunt (ossuaire) ou avec le dépôt de résidus. Ce n'est sans doute pas un hasard si les structures mixtes sont majoritaires dans les contextes les plus anciens, en l'occurrence autour de l'ère et dans la première moitié du $\mathrm{I}^{\mathrm{er}}$ s. apr. J.-C. (voir chapitre IV) : les premières structures de dépôts réunissent les deux banquets, ou en tout cas associent le souvenir du premier (résidus) aux restes de l'individu (ossuaire), exactement comme dans les dépôts courants de l'âge du Fer, mais en le représentant différemment (mobilier calciné directement issu du bûcher). Dans cet esprit, les inhumations romaines à mobilier rassembleraient également de fait les deux repas, celui du banquet funéraire représenté par les vases détruits, et le banquet annuel des Parentalia illustré par le mobilier intact ou mutilé. Le mode de dépôt de l'ensemble reproduit d'ailleurs en partie les gestes représentés dans certains dépôts secondaires de crémation du second âge du Fer et dans les bûchers de l'époque romaine (vases brisés) et respecte globalement la séparation des vases par fonction.

La deuxième implication est que l'étape de la crémation acquiert un rôle extrêmement important à l'époque romaine, rappelant en cela les grandes cérémonies qui se tenaient apparemment dans certains contextes exceptionnels, aristocratiques, du $\mathrm{II}^{\mathrm{e}}$ s. av. J.-C. En effet, les bûchers en fosse pourvus d'un abondant mobilier primaire, qui pendant longtemps ont été supposés constituer une inno- vation en Gaule (Struck, 1993 ; Bel, Tranoy, 1993a et b), préexistent à la conquête, comme en témoignent les sites de Pulvérières et de Saint-Laurent-la-Conche. Ces contextes indiquent également que les pratiques complexes mises en évidence dans les bûchers en fosse de l'époque romaine, caractérisées par la gestion du bûcher, des résidus et de l'ossuaire, sont en place en Gaule dès le $\mathrm{II}^{\mathrm{e}} \mathrm{s}$. av. J.-C.

Il nous faut cependant souligner que toutes les tombes remarquables de l'âge du Fer, liées à une cérémonie complexe, ne sont pas des crémations. En Auvergne, par exemple, si c'est le cas à Pulvérières ( $\mathrm{II}^{\mathrm{e}} \mathrm{s}$.) et à Malintrat (seconde moitié du ${ }^{\mathrm{er}} \mathrm{s}$.), les tombes du II ${ }^{\mathrm{e}} \mathrm{s}$. d'Aulnat/ Gandaillat, qui se distinguent par leur mobilier (architecture élaborée de la tombe, présence d'armes, d'un mobilier abondant et diversifié et, dans un cas, d'un animal sacrifié), sont des inhumations, les dépôts de crémation contemporains relevés sur le site se résumant pour la plupart à des petites fosses remplies de résidus exempts de mobilier primaire et dépourvues de mobilier secondaire. Néanmoins, si l'on réunit toutes les séries, la quantité et la variété du mobilier est nettement plus importante sur les bûchers ou dans les dépôts de crémation que dans les inhumations. Les différences de traitement (inhumation/crémation) parmi les individus, dont le statut élevé est explicitement évoqué par l'appareil funéraire, traduisent-elles ainsi une hiérarchisation au sein des élites ? La pratique de la crémation qui s'accompagne d'un mobilier primaire toujours nombreux et varié, et notamment l'usage du bûcher en fosse, sont de toute évidence limités à un petit nombre de personnes et sans doute à une partie de la société. À l'extrême fin du II $^{\mathrm{e}}$ s. et au tout début du I $^{\mathrm{er}}$ s., l'un des attributs de certains groupes qui pratiquent le bûcher en fosse est le char, puisque les résidus de crémation contenus dans les structures de Pulvérières et de Saint-Laurent-la-Conche (100-80 av. J.-C.) en conservent des vestiges calcinés. Les données archéologiques qui nous sont parvenues de la tombe à char de Verna (100-80 av. J.-C.), fouillée au début du XIX ${ }^{\mathrm{e}}$ s. en Isère (Perrin, Schönfelder dir., 2003), ne permettent malheureusement pas de déterminer si la fosse, de plan carré d'un peu moins de 2 m de côté, a servi à établir le bûcher.

La composition de la vaisselle est proche dans les deux périodes, caractérisée par de nombreux vases à solides, à liquides, mais aussi par la faiblesse des récipients utilisés pour la préparation culinaire qui, dans nos séries, ne constituent que $13 \%$ des vases à l'âge du Fer (Deberge, Orengo, 2007) et moins de $15 \%$ à l'époque romaine. Les proportions relatives du service des liquides et de celui des 


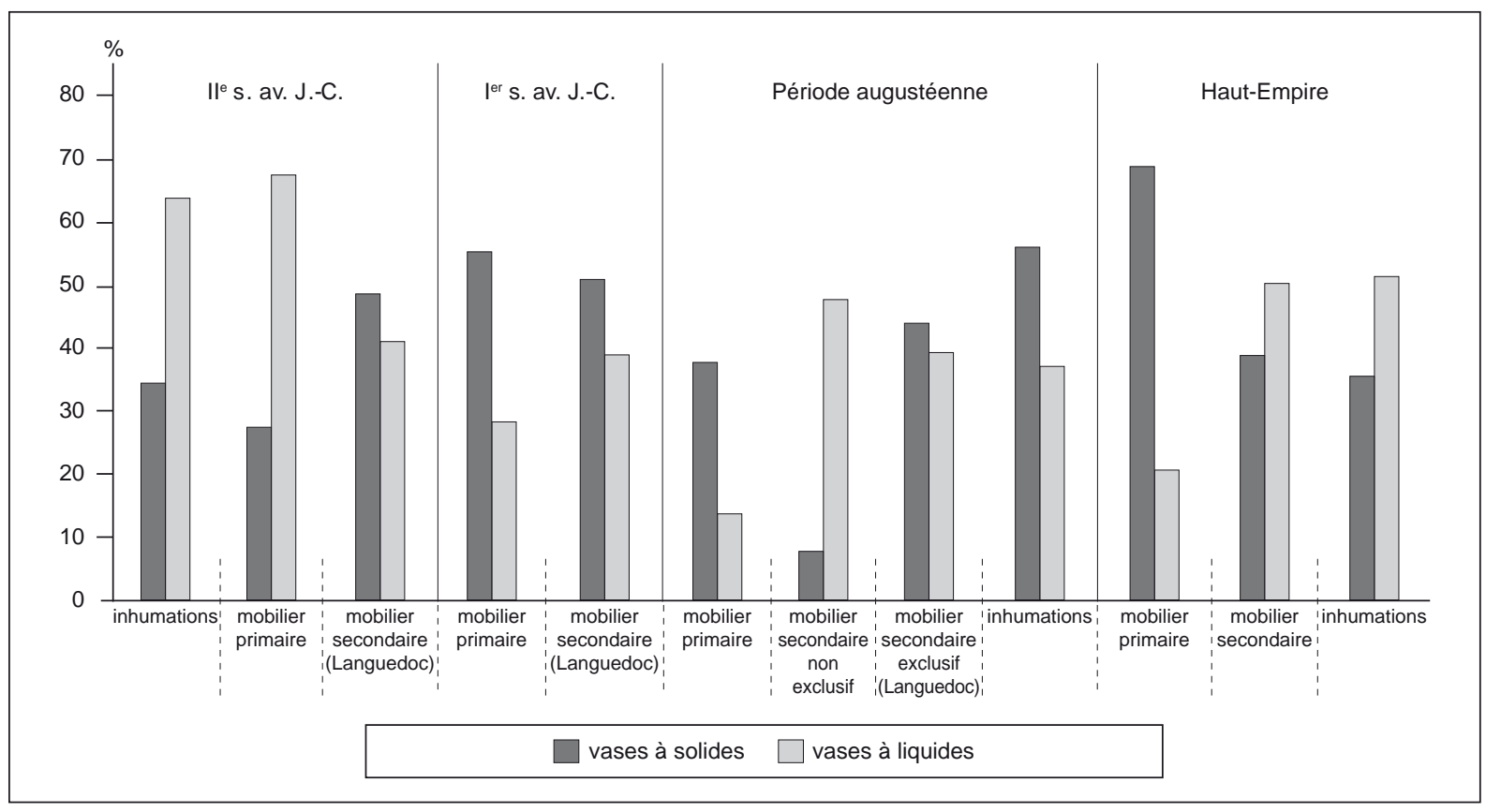

Fig. 217 - Évolution des fonctions des vases à liquides et à solides dans les structures funéraires du II ${ }^{e}$ s. av. J.-C. au I ${ }^{e r}$ s apr. J.-C. (DAO : F. Blaizot, Inrap).

solides varient cependant entre le $\mathrm{II}^{\mathrm{e}} \mathrm{s}$. av. J.-C. et le $\mathrm{I}^{\mathrm{er}} \mathrm{s}$. apr. J.-C. (fig. 217). Dès la fin du $\mathrm{II}^{\mathrm{e}}$ s., les vases à liquides, qui dominent la vaisselle des inhumations et des bûchers en Auvergne, sont supplantés par les vases à solides (id., ibid., 2007), conformément à ce qui se passe sur les sites d'habitat. Ces changements ne sont en revanche pas observés en Languedoc, où la vaisselle du mobilier secondaire des dépôts de crémation, le seul représenté, est illustrée par un certain équilibre entre les deux fonctions. À l'époque augustéenne, la vaisselle placée sur le bûcher, en Auvergne et en RhôneAlpes, maintient la suprématie du service des solides, alors que le mobilier secondaire, qui fait son apparition, restaure la prévalence du service des liquides. En Languedoc, où le mobilier primaire est toujours absent autour de l'ère, les deux fonctions restent encore également réparties dans le mobilier secondaire, mais les faits changent dès la fin de cette période : les solides sont majoritaires dans la vaisselle qui apparaît alors sur le bûcher et les liquides s'avèrent plus nombreux dans le mobilier de la structure de dépôt. Ces constats nous conduisent à envisager que la fonction du mobilier secondaire diffère à l'âge du Fer et à l'époque romaine ; très complet, de composition identique à celui qui est présent sur le bûcher des populations qui pratiquent ce rite, il joue probablement le même rôle que ce dernier et se rapporte au repas des funérailles stricto sensu. À l'époque augustéenne, on peut supposer qu'il représente les deux étapes, celle du repas des funérailles et celle du repas de commémoration, puisqu'il réunit dans une seule structure les accessoires dissociés par les groupes culturels qui effectuent les deux modes de dépôts (sur le bûcher, puis dans la tombe), d'où l'équilibre des deux fonctions. Avec cette hypothèse, se pose de nouveau la question des rites de commémoration à l'âge du Fer : ne se pratiquent-ils pas ou ne sont-ils pas représentés dans la tombe ? En d'autres termes, faut-il ou non attendre l'époque romaine pour passer à un système funéraire inscrit dans la durée ?

L'examen de la répartition des fonctions souligne une fois de plus la parenté entre le mobilier secondaire des dépôts de crémation et le mobilier des inhumations : ils suivent le même schéma au Haut-Empire, tandis qu'à l'âge du Fer, la composition du mobilier des inhumations est identique à celui du mobilier primaire des bûchers dans les régions où cette pratique a cours. Par ailleurs, le nombre d'inhumations exemptes de vaisselle ou n'en illustrant que la pars pro toto est important au Haut-Empire, ce qui rejoint ce que nous avons déjà évoqué pour l'âge du Fer, à savoir que les étapes du rite funéraire s'avèrent moins illustrées dans les inhumations que dans les structures qui se rapportent à la pratique de la crémation.

À l'époque romaine, il est extrêmement rare que des objets de qualité soient placés sur le bûcher. Concernant la vaisselle, les études réalisées dans le cadre de ce dossier 


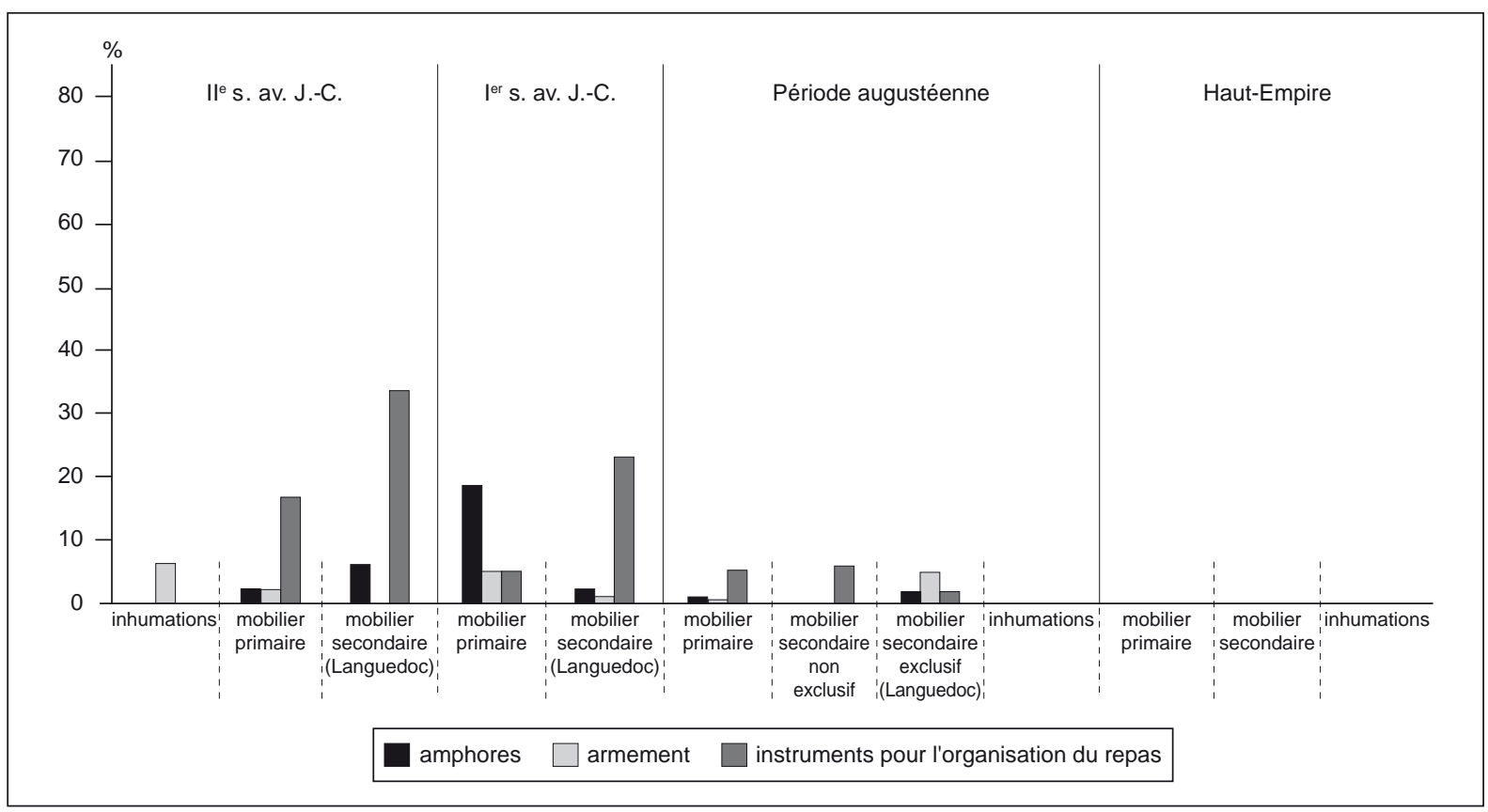

Fig. 218 - Représentation des instruments collectifs du banquet et des objets de statut dans les structures funéraires du II e s. av. J.-C. au I Ir s. apr. J.-C. (DAO : F. Blaizot, Inrap).

montrent, au contraire, que les vases sont sélectionnés parmi les productions de moindre qualité (céramiques sigillées du centre de la Gaule au I ${ }^{\mathrm{er}} \mathrm{s}$.), voire qu'ils présentent des traces d'usure indiquant une provenance directe de la sphère domestique (voir chapitres I, II et IV). Ces caractères sont relevés même au sein des structures les plus ostentatoires (très grands bûchers, mobilier abondant et diversifié...), ce qui les oppose à ceux des contextes de type aristocratique du second âge du Fer (Verna, Saint-Laurentla-Conche, etc.), où est investi un mobilier de qualité. Les bûchers les plus prestigieux de l'époque romaine se distinguent donc des plus modestes plutôt par la mise en scène générale de l'appareil, à savoir l'accumulation de vaisselle et de nourriture (280 vases au col de Ceyssat), la disposition du mort (lits en os et ivoire) et du mobilier (classé et étagé) et par le décor du bûcher, ce dernier s'apparentant parfois à un véritable petit édifice.

Certains ensembles mobiliers des élites du second âge du Fer se caractérisent par la présence d'ustensiles liés à l'organisation du banquet (amphores, couteaux, tranchoirs au $\mathrm{II}^{\mathrm{e}}$ s., puis apparition des seaux ou des cratères pour le mélange du vin et de l'eau, à partir du I ${ }^{\mathrm{er}}$ s., bien qu'un seau soit présent dans la tombe du guerrier d'Aulnat/Gandaillat datée vers 150-100 av. J.-C). En cela, et également par la présence d'objets directement liés au statut social du défunt (éléments de char en Auvergne et en Rhône-Alpes, ou d'objets liés à l'armement en Languedoc et en Auvergne), ces structures funéraires se distinguent fondamentalement de celles du $\mathrm{I}^{\mathrm{er}} \mathrm{s}$. de notre ère dans les mêmes régions, où ces objets s'avèrent très rarement attestés dès le début de l'ère et sont rencontrés de manière exceptionnelle plus tardivement (fig. 218).

Dans nos séries du second âge du Fer, les ustensiles utilisés pour l'organisation du banquet sont placés sur le bûcher systématiquement en association avec des objets qui se rapportent à l'armement. C'est le cas, par exemple, à Malintrat, Pulvérières, Verna et Saint-Laurentla-Conche. Lorsque l'armement fait défaut, les récipients collectifs, s'ils sont présents, semblent avoir été brûlés à part. À Rochefort, sur le site du hameau des Peupliers (fouille inédite G. Alfonso, Inrap), un fossé, partiellement fouillé en bordure de l'ensemble funéraire laténien, comporte de nombreux fragments de céramique ayant subi une forte crémation, mais aucun os humain ; ces fragments se composent d'amphores à vin et de vases de stockage, absents en revanche dans le mobilier primaire des dépôts de crémation, tandis qu'au contraire la céramique peinte (étude inédite de C. Jouannet, Inrap), caractéristique de ces derniers, n'est pas représentée dans le fossé. Des dépôts de faune (deux chiens et un coq entiers, des quartiers de chèvres et un crâne de cheval) proviennent également d'un fossé. Outre des dépôts de résidus de crémation 


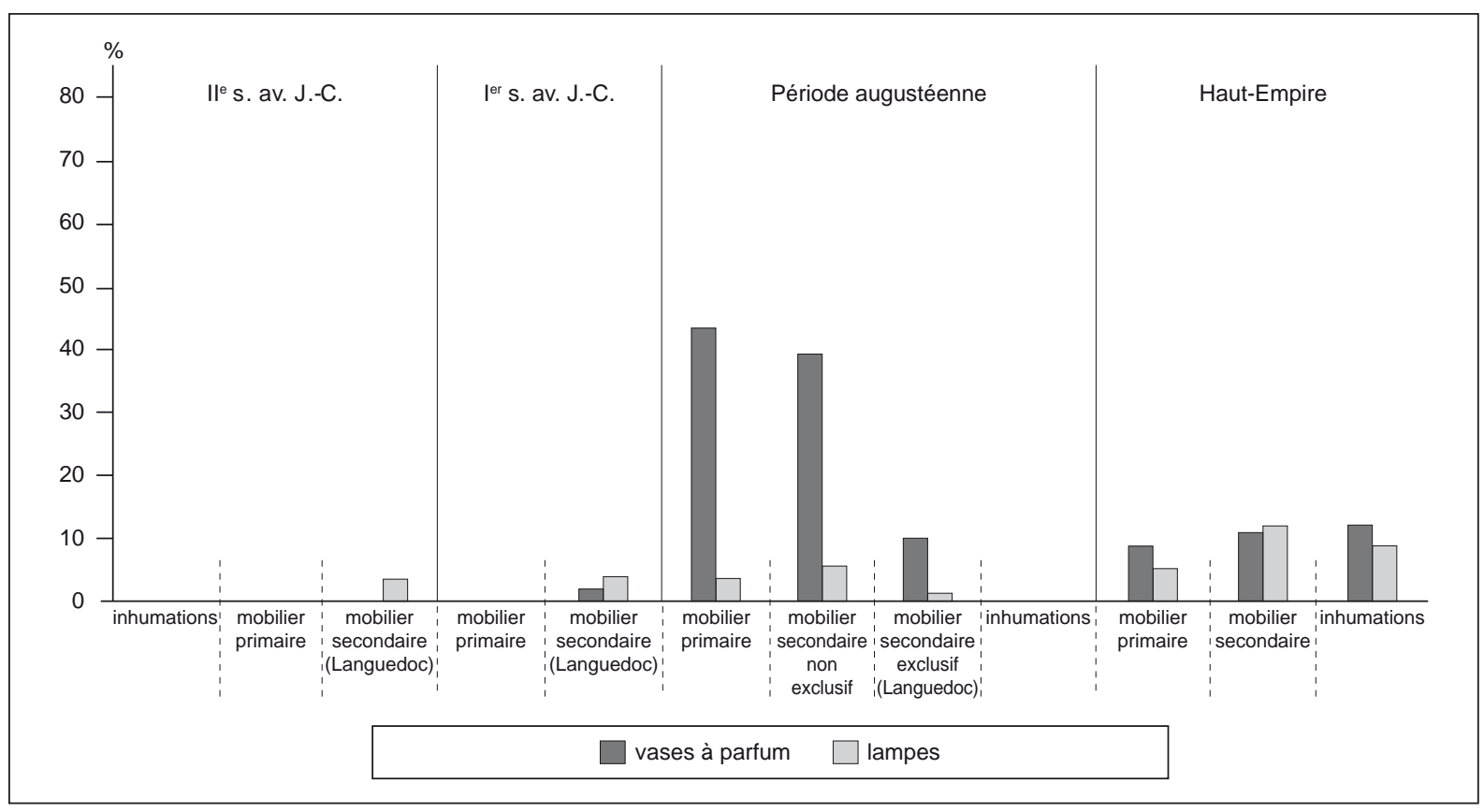

Fig. 219 - Représentation des lampes et des vases à parfum dans les structures funéraires du II ${ }^{e}$ s. av. J.-C. au I ${ }^{e r}$ s apr. J.-C. (DAO : F. Blaizot, Inrap).

(résidus groupés en amas ou comblant toute la surface de la fosse), le site compte deux structures funéraires dont les caractéristiques générales (morphologie, taille, présence de bois carbonisé et organisation du mobilier sur le fond) s'apparentent à des bûchers en fosse ; aucune structure ne livre d'éléments guerriers. Les dépositions pratiquées dans le fossé ne sont pas sans rappeler l'enfouissement des ustensiles collectifs relevés sur certains sites romains comme à la Favorite. Rappelons enfin que les vases à cuire et les amphores sont relevés en situation résiduelle dans les ensembles funéraires du Haut-Empire et que, dès La Tène finale, une dissociation est opérée dans certaines sépultures entre la vaisselle du bûcher et les amphores, les fragments calcinés de ces dernières étant placés à distance du mobilier qui a brûlé avec le mort (voir supra, p. 330, références aux sites de Lamadelaine, Bonnert, Feulen et En Chaplix).

Ainsi, certains défunts de La Tène finale conservent leur fonction sociale de "sacrificateur et de chef du symposium » (Bats, 2002, p. 291), tandis que, dans le courant du premier quart du $\mathrm{I}^{\mathrm{er}} \mathrm{s}$. de notre ère, cette fonction paraît totalement passer aux vivants. Le mort est alors avant tout un consommateur convié au banquet par les vivants, au même titre que les dieux.

Parmi l'ensemble des accessoires de l'appareil funéraire, les vases à parfum et les lampes, auxquels les structures funéraires de l'époque romaine font une place particulière, constituent une réelle nouveauté en Gaule. Apparus très sporadiquement dans le mobilier secondaire des tombes languedociennes de La Tène finale, ils ne sont pas relevés en Rhône-Alpes et en Auvergne pour cette période (fig. 219). Le vase à parfum connaît en revanche un essor considérable à l'époque augustéenne, tant dans le mobilier primaire que secondaire, notamment à Lyon, tandis que les lampes font une apparition timide. Puis, la proportion des vases à parfum baisse légèrement dans ce secteur dans le courant $\mathrm{du} \mathrm{I}^{\mathrm{er}} \mathrm{s}$., alors que les lampes s'avèrent en légère augmentation. En Languedoc, la présence des parfums se maintient dans des proportions équivalentes dès l'époque augustéenne et sur tout le $\mathrm{I}^{\mathrm{er}} \mathrm{s}$., où elle tient une place moins importante qu'à Lyon.

La fonction de ces objets dans le rite funéraire a été interprétée à partir des sources littéraires. Les parfums, apparemment empruntés aux rites grecs, sont destinés à masquer les odeurs du bûcher et plus largement à garder les vivants de la corruptibilité de la mort, tout en restaurant la part humaine du défunt (Scheid, 1984, p. 120-121). Quant à la présence des lampes, J. Scheid la rapporte à la notion d'inversion du réel, que nous avons évoquée dans les chapitres précédents à propos des objets placés à l'envers ; la mort est ténèbres, opposée au monde diurne des vivants et, dans le cadre des funérailles, les endeuillés marquent leur ségrégation provisoire par la lumière qui a pour effet 
d'inverser la réalité (id., ibid., p. 122-125). Ces objets restent, quoi qu'il en soit, fortement rattachés aux traditions méditerranéennes ; très fréquents en Méditerranée occidentale, ils s'avèrent beaucoup plus rares dans les contextes septentrionaux et en Suisse.

Les monnaies ont été peu abordées dans ce dossier en dehors du chapitre sur l'inhumation. N'ayant pas effectué le recensement des monnaies sur l'ensemble de nos séries, nous ne pouvons qu'en tirer de grandes lignes. Les monnaies apparaissent plus courantes dans les inhumations (HautEmpire et surtout Bas-Empire) que dans les structures liées à la crémation (11 structures sur 123, voie de l'Océan à Lyon, cf. Frascone, 1999, p. 114 ; 36 sur 278 à la Favorite, cf. Tranoy, 1995b, p. 774 ; 12 sur 238 au Valladas, cf. Bel et al., 2002, p. 153). Dans tous les cas, elles semblent liées au corps, car les exemplaires recueillis en contexte de crémation sont toujours brûlés. Dans les inhumations, leur situation, relativement au corps, s'avère tellement variable (au niveau des membres supérieurs, inférieurs, du tronc, du visage, voire dans un vase ou portées en amulettes) que leur fonction dans le rite funéraire reste difficile à appréhender. Dans la plupart des cas, elle paraît indiquer que le défunt conservait les pièces dans une poche ou une bourse, et, dans d'autres, que ces éléments participaient à la mise en scène du corps puisqu'elles semblent avoir été posées sur les paupières et sur la bouche, comme à Malbosc (Blaizot et al., 2008). C'est pourquoi nous hésitons à abonder dans le sens de l'hypothèse habituelle de l'obole à Khárôn, évoquée dans un texte grec tardif de Pausanias (115-180 apr. J.-C.), qui, par ailleurs, se réfère lui-même à un mythe antérieur d'un millénaire.

\section{L'IMAGE SOCIALE DES PRATIQUES FUNÉRAIRES DU HAUT-EMPIRE}

$\mathrm{Si}$, en théorie, à une fonction réelle, religieuse et technique, correspondent un choix culturel et une image sociale, l'interprétation historique et sociale des faits examinés, qui se révèle l'un des objectifs de cette réflexion, est délicate. Certains codes peuvent avoir une double fonction et d'autres, de même nature, se rapporter à des registres différents. Par exemple, la vaisselle peut traduire la consommation, par le mort, du repas funéraire, mais aussi l'importance sociale du défunt, au moyen de la quantité (plus rarement de la qualité) des récipients et de la diversité des denrées mises en ouvre. Au sein de cette vaisselle, une part peut également correspondre à la quantité d'invités qui ont partagé de manière effective ce repas, ce qui renvoie une fois encore, mais d'une façon plus réelle, à l'image sociale du défunt. Enfin, le déroulement des rites n'étant pas fixé, il est probable que certaines pratiques relèvent d'une démarche individuelle et l'interprétation d'un geste, d'une configuration, est toujours incertaine. Dans la volonté manifeste de l'auteur du testament du Lingon de détruire son équipement de chasse (seconde moitié du $\mathrm{II}^{\mathrm{e}}$ s. apr. J.-C.), on peut lire un désir orgueilleux de faire étalage de ses biens, ou bien un acte isolé et désespéré de marquer le renoncement aux plaisirs de la vie, ou encore l'impossibilité superstitieuse, pour les descendants, d'utiliser les objets personnels du défunt.

Les rares objets de qualité rencontrés parmi les vestiges du bûcher ont un caractère personnel, puisqu'ils se rapportent essentiellement à la toilette ou à la parure. A contrario, la vaisselle impliquée dans les funérailles, même les plus grandioses, n'est plus un mobilier de prestige ${ }^{52}$. On n'est plus à l'heure où le statut du défunt s'exprime par la qualité des objets détruits, contrairement à ce qui est observé dans les milieux aristocratiques de l'âge du Fer (Poux, 2002b, p. 105). La possibilité de détruire ses richesses pour marquer sa puissance apparaît comme une expression révolue. Par l'importance numérique des mets et de la vaisselle, est traduite la quantité des invités et donc l'envergure des relations sociales. Ainsi, la position sociale s'exprime moins par l'étalage de la richesse du défunt que par sa capacité à nouer des relations. Or, si l'image de la position sociale diffère, c'est que la relation de l'individu avec les autres membres de la société n'est plus la même.

En effet, cette dimension sociale est déjà présente dans les banquets des élites de l'âge du Fer (Poux, 2002a, p. 345), mais on peut supposer qu'à l'époque romaine, où les cérémonies funéraires de l'ensemble de la société sont recentrées sur la famille, elle se manifeste différemment, par d'autres circuits. La pratique de la distribution somptuaire se fait alors par l'évergétisme (Veyne, 1976, p. 251 et p. 253). Plus modestement, les banquets publics prescrits dans les fondations funéraires pour entretenir le tombeau permettent au défunt de dépasser la mémoire familiale en entretenant sa mémoire publique, puisque ce banquet est offert à un groupe social plus élargi (Schmitt-

52. Dans les régions septentrionales, certaines tombes du début du $\mathrm{I}^{\mathrm{er}} \mathrm{s}$. conservent plus volontiers des objets de prestiges (Ferdière, Villard, 1993 ; Jacques, 2007). En Rhône-Alpes, on peut citer l'ensemble de La Boisse, avec ses amphores et sa vaisselle en bronze, du troisième tiers du I ${ }^{\mathrm{er}}$ s., et celui de la ZAC Galbert à Annecy, qui livre de la vaisselle en bronze (première moitié du $\mathrm{I}^{\mathrm{er}} \mathrm{s}$.) ; cependant, la présence de plusieurs céramiques produites sur la région du Limès dans la structure de La Boisse, l'exclut des références régionales. 
Pantel, 1982, p. 181). P. Schmitt-Pantel compare d'ailleurs les deux comportements, celui du citoyen de l'Antiquité et celui du guerrier des temps antérieurs, dans la mesure où la mémoire publique rejaillit sur les descendants du défunt et joue un rôle dans la reproduction du système social (id., ibid., p. 183). Toutefois, comme le démontrent bien A. Testart et J.-L. Brunaux, si ces deux modes de disposition de la fortune du mort ont, par leur caractère ostentatoire, le même objectif de proclamer le prestige du défunt et de son groupe, celui qui détruit des biens prestigieux traduit un désir de domination sur la société, tandis que celui qui distribue par des donations ou dans le cadre de fondations funéraires replace l'individu au centre de la communauté à laquelle ce dernier rend service (Testart, Brunaux, 2004, p. 178).

Enfin, par-delà cette évidente affirmation d'un certain pouvoir social, transparaît également une dimension plus personnelle, comme le montrent non seulement le caractère individuel $\mathrm{du}$ rare mobilier de prestige et la situation centrale du corps dans le dispositif funéraire, mais aussi les inscriptions et les testaments, dans lesquels on sent la volonté, dans cette société dramatiquement dépourvue d'espérance, d'échapper au temps qui passe, de marquer sa présence au monde par le souvenir (la taille et la situation des monuments, les inscriptions) ; ce dernier s'exprime aussi par ce désir d'entretien du tombeau qui « affirme une valeur individuelle »(Lavagne, 1987), par le respect des rites de commémoration et, bien sûr, par l'évergétisme funéraire qui, comme le souligne P. Veyne, aboutit à l'immortalisation (Veyne, 1976, p. 248).

$\mathrm{Au}$ milieu du $\mathrm{I}^{\mathrm{er}} \mathrm{s}$. avant notre ère, César est frappé par l'ampleur des crémations en Gaule qui, écrit-il, « ont toute la magnificence et la somptuosité qui conviennent à leur amour du faste »(De bello gallico, VI, 19, 4). Parmi les nombreux modèles funéraires présents en Gaule durant les deux derniers siècles avant notre ère, le bûcher en fosse, présent dans les couches les plus élevées des groupes aristocratiques, émerge nettement dans nos régions, dans les contextes urbains ou associé à des villae. L'ensemble de son appareil laisse envisager que l'élite gallo-romaine copie les cérémonies " aristocratiques » qui avaient cours en Gaule dès 175 av. J.-C. et dont une part avait été élaborée dans des contextes très privilégiés en Orient, comme en témoignent les pratiques relevées dans les bûchers royaux macédoniens à partir du troisième tiers $d u \mathrm{IV}^{\mathrm{e}} \mathrm{s}$., qui consistent à placer l'urne-ossuaire dans le bûcher et à recouvrir de terre ce dispositif et les restes du bûcher (Kottaridi, 1996 et 1999). Or, déjà en Macédoine, ces pratiques font référence aux tradi- tions homériques des funérailles, et ceci jusque dans le $\mathrm{II}^{\mathrm{e}} \mathrm{s}$. alors que le royaume est conquis par les romains (GuimierSorbets, Morizot, 2005, p. 139 et p. 141). C'est comme si, tout au long de l'Antiquité, les élites revenaient sans cesse à ce modèle héroïque, dont le caractère ostentatoire (construction et décor du bûcher, lit, accumulation de biens) et théâtral (destruction par le feu avec l'utilisation préférentielle du bois de hêtre et de sapin qui produit des flammes hautes et claires) contribue à marquer le prestige du défunt et de sa famille. À chaque fois, les communautés en adaptent les variables et en réinterprètent les symboles en fonction des discours mythique et social du moment ${ }^{53}$. On retrouve, à une autre échelle, la nuance entre le cadre général de l'obligation rituelle et les pratiques qui relèvent des coutumes, ces dernières n'étant pas exemptes d'innovations.

Une autre variable de l'appareil funéraire, dont on a peu parlé pour l'instant, est constituée par les monuments. Là encore, est observé un glissement du discours d'un symbole à l'autre avec, d'un côté, le bûcher ostentatoire mais éphémère et, de l'autre, la pérennisation de la tombe par ce que C. Landes n'hésite pas à qualifier d'exhibitionnisme monumental (Landes, 2002, p. 10). Jamais il n'a pu être démontré que ces bûchers, non monumentalisés, et ces édifices fonctionnent ensemble pour un même défunt. Ils coexistent dans des proportions différentes quasiment tout au long du Haut-Empire, même si les monuments sont présents dès les premiers temps jusque dans les dernières décennies du Haut-Empire, et même au-delà, tandis que les bûchers en fosse se généralisent apparemment plus tardivement et sont abandonnés avant la fin du Haut-Empire. Cependant, en admettant que ce sont là deux formes différentes d'ostentation, sont-elles pour autant exclusives ? Rien n'est moins sûr, dans la mesure où elles n'ont pas le même objectif à terme ; l'une se rapporte encore au présent, c'est la dernière manifestation du mort dans sa gloire immédiate puisqu'il exalte le prestige du défunt par la capacité de la famille à organiser une cérémonie et par le luxe de sa mise en scène, tandis que l'autre pérennise la réussite sociale du défunt, exprime son statut et donc plus largement affirme la position des survivants sur la durée. Cette forme d'expression du statut prend diverses formes, parmi lesquelles la localisation du tombeau n'est pas de moindre importance. Corrélée à la possession d'un bien foncier, la tombe, implantée dans un domaine privé ou établie sur un terrain acheté à grands

53. Pour des périodes un peu plus tardives, la fascination exercée par l'Empire byzantin sur les populations franques et alamanes est perceptible dans la mise en scène du corps relevée dans les sépultures de la seconde moitié du VI ${ }^{\mathrm{e}}$ s. (Schach-Dörges, 2005). 
frais en bordure d'une voie publique, rappelle aux vivants le niveau social du défunt et de sa famille ; plus largement, en s'identifiant ainsi à sa propriété, le commanditaire ancre sa mémoire au sein d'un territoire (Goudineau, 1998 ; Lafon, 2002). Dans cette société dont l'organisation est fondée sur des relations de dépendance, le choix du lieu d'élection de sa sépulture et de la structuration de son espace funéraire n'est pas anodin. Que l'on ouvre ce dernier à un cercle plus large que la famille stricto sensu, par exemple en y introduisant le personnel (Eck, 1987, p. 73) ou que l'on se regroupe par corporations (tombes de sévirs à Lyon ou à Narbonne), on entend autocélébrer sa mémoire sociale (importance et hiérarchie de la maison du propriétaire dans le premier cas, rôle dans la vie publique dans le second).

Le modèle du bûcher ostentatoire tombe rapidement en désuétude, comme le montre le cas de Lyon. Sa " démocratisation » marquée par son adoption par des groupes moins privilégiés (les notables puis la «bourgeoisie » commerçante et artisanale se l'accaparent) aboutit à la diversification des pratiques, puis à l'appauvrissement de l'appareil général et peut-être aussi aux modalités de fonctionnement, en témoignent les restrictions des caractères ostentatoires du système (la taille est marquée par une plus grande amplitude des valeurs lorsque l'on avance dans le temps ; le nombre de bûchers pourvus d'un mobilier moins abondant augmente...). À terme, il disparaît. L'aspiration à copier des modèles prestigieux est tout aussi manifeste dans les monuments, contrairement à l'âge du Fer où les grands tumulus sont réservés à l'élite. Élever un tombeau signe la réussite sociale du citoyen, ce que fait remarquer $\mathrm{X}$. Lafon en rappelant que ce sont les affranchis qui développent le plus de faste autour de leurs tombeaux (Lafon, 2002). Dans le même esprit, E. M. Steinby montre que l'on copie les monuments funéraires en réduction (Steinby, 1987, p. 109-110), voire qu'on les représente sur les stèles lorsque l'on ne dispose que de faibles moyens, tandis que N. Purcell interprète la présence de tombeaux modestes parmi les beaux monuments comme l'expression de la prospérité d'une société dont le bien-être dépend en partie du statut des notables (Purcell, 1987, p. 40).

Ce n'est peut-être pas par hasard si à Lyon, sur la rive gauche du Rhône, les autels funéraires se développent justement après la seconde moitié $\mathrm{du} \mathrm{II}^{\mathrm{e}} \mathrm{s}$., au moment où les bûchers en fosse amorcent sensiblement leur déclin. En deux siècles, on est passé ostensiblement à une logique générale différente : d'une ostentation cérémonielle éphémère à la pérennisation d'une structure monumentalisée destinée à marquer sa réussite sociale dans le temps, même si dans les deux cas, la mort reste orgueilleuse. Cette transposition est sans doute l'un des traits les plus frappants de l'évolution des pratiques funéraires ; d'une certaine manière, on peut dire que le bûcher en fosse, avec le faste qui l'accompagne, constitue le dernier avatar de l'idéal protohistorique.

\section{DU HAUT-EMPIRE À L'ANTIQUITÉ TARDIVE : VERS UNE NOUVELLE IMAGE SOCIALE?}

\section{CONTINUITÉS ET DISCONTINUITÉS OBJECTIVES}

Nul besoin de revenir sur le fait que les pratiques funéraires du $\mathrm{III}^{\mathrm{e}} \mathrm{s}$. basculent brusquement et de manière radicale dans l'inhumation (voir supra, chapitre I, p. 20-25).

Les séries d'inhumations examinées dans le cadre de ce dossier mettent en évidence une grande diversité des pratiques qui, comme au Haut-Empire, se traduit avant tout par une variabilité des matériaux du rite.

On retrouve la coexistence de « sépultures nues » et de tombes plus ou moins pourvues de mobilier, dont la majeure partie, constituée de vaisselle, se réfère aux repas funéraires. Parmi ces dernières, certaines sont remarquables par la complexité de leur appareil ; celui-ci témoigne de gestes identiques à ceux pratiqués au Haut-Empire, transcrivant les diverses étapes du rite de séparation : bris, mutilations de vases, mise en scène des objets, dépôts de lampes... (sites du Pillon à Marennes, de Malbosc à Montpellier, des Clapiès à Villeneuve-lès-Béziers, $c f$. Manniez, 1999).

$\mathrm{Au}$ Bas-Empire, les changements directement perceptibles ont trait au dispositif du corps. Les individus sont en effet systématiquement, à de très rares exceptions près, placés sur le dos et la position du corps se caractérise par un « arrangement » des membres. Ceux de l'étage inférieur sont en rectitude, parallèles à l'axe longitudinal du corps ; les membres de l'étage supérieur sont certes disposés de manière variable selon les séries et les individus au sein de ces dernières, mais leur position est le fait d'une intervention, contrairement à celle, aléatoire, observée à La Tène finale ou au Haut-Empire, qui assez souvent résulte de toute évidence des conditions de dépôt. Une autre différence concerne la tombe elle-même ; si l'inhumation à même la fosse, prévalente aux époques précédentes, est toujours pratiquée, la grande majorité des dépôts est réalisée dans des contenants dont la nature varie selon les régions, les architectures de bois (cercueils et coffrages) étant globalement plus prisées dans la partie septentrionale de la zone étudiée que dans la partie méridionale qui privilégie les coffrages de tegulae ou composites. 
L'ensemble de ces caractères, qui distinguent automatiquement les inhumations tardo-antiques de celles des époques protohistorique et du Haut-Empire, doit-il être mis en relation avec le nouveau rapport que l'individu entretient avec son corps, "reconnu comme partie intégrante de la personne humaine » (Stroumsa, 2005, p. 55) ? L'autre possibilité serait que les formes de la tombe à inhumation, au Bas-Empire, transposeraient celles des dépôts de crémation de type ossuaire (la structure de dépôt semble le plus souvent aménagée et les os sont rangés dans un coffret ou dans un vase parfois placé dans une boîte).

Avec le mobilier, une modification concerne la quasidisparition des vases à parfum dans la seconde moitié du $\mathrm{III}^{\mathrm{e}} \mathrm{s}$. On pourrait supposer qu'elle est liée à l'abandon de la crémation, puisque les parfums semblent avoir été utilisés pour masquer les odeurs des chairs calcinés, mais les vases qui s'y rapportent font également partie du mobilier secondaire et participent aussi à la pratique de l'inhumation. Sans doute faut-il revenir à l'hypothèse de J. Scheid selon laquelle le parfum protège les vivants de la souillure de la mort et rappelle l'humanité du défunt (voir supra, p. 334), ce qui rapporte alors peut-être cette disparition du vase à parfum à la nouvelle perception du corps.

Apanage de l'aristocratie, puis indissociable du sacrifice, le vin qui joue un rôle continu dans le rituel funéraire de l'extrême fin de l'âge du Fer jusque dans l'Antiquité tardive est attesté par les amphores déposées dans les sépultures du $\mathrm{I}^{\mathrm{er}}$ s. av. J.-C., puis par les vases à liquides brisés sur le bûcher en fin de crémation et par les cruches à vin des structures de dépôt du Haut-Empire (inhumations et crémations) (Blaizot, Bonnet, 2007, p. 216-218). Jusqu'à l'Antiquité tardive également, les gobelets et les cruches sont les récipients privilégiés, fréquemment installés au niveau de la tête du défunt (Blaizot et al., 2001, p. 314).

La confrontation de nos séries nous invite aujourd'hui à nuancer l'affirmation selon laquelle la pratique de déposer du mobilier dans les tombes décroît à l'Antiquité tardive et, avec elle, le nombre de vases par tombe (Blaizot et al., 2001 ; Raynaud, 2006). Tout d'abord, la part des tombes à mobilier sur la totalité des inhumations n'est pas supérieure au Haut-Empire à celle relevée au Bas-Empire, pas plus que ne l'est celle des tombes à vase unique relativement à celle des sépultures pourvues de plusieurs récipients. Il en est de même si l'on compare les données des inhumations avec celles qui se rapportent au mobilier secondaire dans la pratique de la crémation (structures pourvues de mobilier secondaire et nombre d'objets qui le constituent), la comparaison étant justifiée par le fait que nous avons établi une identité de fonction entre ces deux types de dépôt. La différence n'est d'ailleurs significative que si l'on considère le mobilier primaire des structures ayant trait à la pratique de la crémation ; la part des inhumations dépourvues de mobilier apparaît alors bien plus importante, tant au HautEmpire qu'au Bas-Empire, ce qui alimente l'hypothèse que nous avons déjà émise plus haut par d'autres arguments, à savoir que le mobilier primaire des crémations illustre une étape du rite différente de celle transcrite par le mobilier secondaire et par celui des inhumations. Par ailleurs, l'imprécision de nos datations au sein de l'Antiquité tardive nous invite à une plus grande prudence. En somme, si une évolution en ce sens a pu être mise en évidence sur un même site (par exemple au Verdier, à Lunel-Viel, cf. Raynaud, sous presse), le phénomène, pris dans sa globalité, semble plutôt transcrire une variabilité des pratiques selon les groupes, et celle-ci est observée jusque dans le dernier tiers du IV ${ }^{\mathrm{e}} \mathrm{s}$. Au final, le seul fait établi est que les dépôts de vases, de lampes et de faune disparaissent complètement autour du milieu du V $\mathrm{V}^{\mathrm{e}}$ s. dans le Midi (Raynaud, 2006, p. 151) et peut-être un peu plus tôt en Rhône-Alpes et en Auvergne. C'est ce phénomène qui doit retenir notre attention et nous proposons de discuter cette évolution, en postulant que la disparition du mobilier s'inscrit dans la continuité du choix, réalisé deux siècles plus tôt, en faveur de l'inhumation.

Pour ce qui concerne les espaces funéraires, on rencontre en grande partie les mêmes schémas qu'au Haut-Empire, avec des tombes isolées et des petits groupes de sépultures établis sur une courte durée liés à des établissements, souvent placés en bordure des routes ou dans le finage des habitats. Tout au long de l'Antiquité tardive et jusqu'à l'aube $\mathrm{du} \mathrm{XI}^{\mathrm{e}}$ s., coexistent les anciens et le nouveau modèles, ce dernier étant illustré par l'importante innovation que constitue, dans certains contextes, la tombe de martyr liée à l'apparition du sanctuaire (basiliques funéraires suburbaines). Notre intention ici n'est pas de rouvrir le dossier du cimetière chrétien, sinon pour souligner certains aspects qui intéressent directement notre propos et rappeler que le terme de koimeterion, qui désigne le cimetière communautaire - chrétien - à partir du VI ${ }^{\mathrm{e}}$ s., est employé préalablement pour désigner la tombe d'un martyr (Rebillard, 1993). Ce glissement est lourd de sens pour ce qui concerne la genèse du cimetière médiéval. En contexte urbain, la séparation de l'espace funéraire est, à l'image du Haut-Empire, opérée entre l'espace urbain proprement dit et le suburbium, dans lequel coexistent tombes, habitat et activités économiques (voir chapitre V). Les modalités en sont cependant parfois différentes : dans beaucoup de cas, le lieu funéraire 
est fixe, dans la mesure où c'est un même espace qui se développe sur une certaine durée, contrairement au HautEmpire (dans nos régions) où les espaces funéraires sont le plus souvent caractérisés par la juxtaposition de noyaux de très courte durée à la dynamique saltatoire. L'image du Bas-Empire est plus nettement, mais non exclusivement, celle d'une polarisation des secteurs funéraires à plus large échelle (Guyon, 2001) et les discontinuités avec ceux de la période antérieure sont très majoritaires. Mis à part les sites de Roanne, de Saint-Irénée (d'après les fouilles, données inédites de Blaizot, 2000 et Ayala, 2001) et du quai Arloing à Lyon, les espaces funéraires établis sur la longue durée sont inexistants au Haut-Empire dans nos régions. Il en est de même dans les campagnes, et peu de sites, dont celui des Plantée à Briord, échappent à ce modèle. Plus fréquents sont les espaces funéraires où sont juxtaposés des ensembles du Haut- et du Bas-Empire, mais caractérisés par une solution de continuité sur un ou deux siècles (par exemple la Contrescarpe, Saint-Just, la Butte, rue du Chapeau-Rouge à Lyon, la Grande Borne à ClermontFerrand, Grange Neuve à Allan...). Ce phénomène n'est en réalité que le reflet de la dynamique des espaces funéraires qui offrent l'image trompeuse d'un ensemble sépulcral discontinu, alors qu'en réalité il ne s'agit que de petits secteurs occupés tour à tour sur une zone plus ou moins restreinte, dont nous ne connaissons qu'une partie. À Lyon d'ailleurs, ce sont globalement les mêmes zones qui sont utilisées pour les morts. Les sites des Girardes à Lapalud, de Saint-Fréjus à Marennes ou encore de Saint-Just à Lyon, fouillés sur de grandes surfaces, le montrent bien : ces secteurs se situent à distance les uns des autres, sans se chevaucher. Ces constats laissent envisager que le concept d'ensemble communautaire n'existe pas vraiment ou, en tout cas, qu'il correspond à un schéma rarissime avant le $\mathrm{IV}^{\mathrm{e}} \mathrm{s}$., époque à laquelle il apparaît cependant encore largement minoritaire. Il n'en reste pas moins qu'en contexte rural, les ensembles funéraires de longue durée créés ex nihilo au $\mathrm{IV}^{\mathrm{e}}$ s., souvent sur un habitat ruiné (pars rustica des villae, notamment), deviennent plus nombreux ; parmi eux, certains perdurent au moins jusqu'à l'époque carolingienne, parfois en dépit de l'absence avérée d'un sanctuaire. Dans les cas où cela a pu être démontré, il semblerait alors que l'ensemble funéraire se déplace lors de la création d'un sanctuaire aux alentours, comme le montre par exemple le site des Horts à Lunel-Viel (Raynaud dir., sous presse).

C'est surtout par ce large type d'ensemble funéraire que se situe l'amorce d'un véritable changement dans nos régions : la sépulture s'ancre non plus dans la propriété privée, auquel le défunt s'identifie, mais dans une communauté dont il fait partie, que le lieu funéraire soit ou non fixé par les symboles de cette dernière (martyr, sanctuaire). Si la tombe antique est confondue avec un lieu de droit privé et tend à exalter l'image sociale du défunt et de sa famille, dans le cimetière qui s'amorce, elle se recadre sur la personne humaine et s'intègre en un lieu public. Sur cet aspect, sans doute est-il intéressant de préciser qu'au $\mathrm{V}^{\mathrm{e}} \mathrm{s}$., apparaît un texte relatif à la protection des corps dans le droit romain et que cette mesure doit être distinguée de celle du Haut-Empire qui s'applique à la protection du seul tombeau (Thomas, 1999, p. 96). Même si la tombe reste un lieu de mémoire, l'individualité prend le pas sur la distinction et, dans certains cas, la communauté sur la propriété. Le corps, qui fait partie intégrante de l'individualité et celle-ci qui s'exalte et s'élargit dans la communauté apparaissent donc comme les éléments d'une évolution majeure de l'organisation funéraire, qui n'empêche pas, en contrepartie, le maintien des modèles antérieurs.

\section{ÉVOLUTION DES PRATIQUES FUNÉRAIRES}

Si l'on s'en tient aux grandes lignes, il semble que la modification qui se manifeste dans les pratiques funéraires se produit sans heurts ; elle relève ainsi plutôt d'une évolution que d'un réel changement, le passage à un seul mode de traitement du corps, l'inhumation, n'impliquant apparemment pas un profond bouleversement du rite.

Cette conclusion demande toutefois, pour être validée, d'examiner les faits plus en détail. En effet, bien que les traits formels des pratiques funéraires du Haut-Empire paraissent globalement en partie maintenus à l'Antiquité tardive, on peut s'interroger sur le sens de l'ensemble de cet appareil, à savoir s'il a ou non acquis une autre raison d'être.

Ce qui frappe tout d'abord dans nos données, c'est le contraste entre des tombes ou des groupes de tombes, dont le contenu transcrit les mêmes gestes que ceux relevés au Haut-Empire (dépôt d'objets, de viandes, vases complets intacts ou mutilés, vases brisés, lampes sur les sites du Pillon à Marennes, de Malbosc à Montpellier, de la Butte à Lyon...), et d'autres, dépourvues de cet appareil, mais dont parfois des vestiges issus de l'environnement proche (un vase brisé au-dessus de la tombe, des fosses contenant de la vaisselle brisée et des os d'animaux) attestent de rites en relation avec le repas funéraire (par exemple les sites de Saint-Just et de Saint-Laurent à Lyon, de Chabannes aux Salelles...). Il est important de souligner que ces différences 
de traitement ne sont pas corrélées aux divers contextes sépulcraux : les deux types de pratiques coexistent tant en milieu rural qu'en contexte périurbain et, dans le second cas, aussi bien dans des contextes chrétiens attestés (basiliques funéraires) que dans les espaces funéraires dépourvus de sanctuaires. Toutefois, les tombes largement dotées en vaisselle avec une mise en scène complexe sont absentes des contextes de basilique dans les séries que nous avons examinées. L'absence de récipients dans les tombes n'est en revanche pas relevée dans toutes les basiliques, comme en témoignent les exemples de vases à liquides (cruches, gobelets, bassins) cités par P.-A. Février sur d'autres sites européens et africains (Février, 1984, p. 173-174). On peut ici évoquer l'hypothèse de P.-A. Février, bien que nous ne la partagions pas, qui lie la présence des vases dans les tombes non pas à une forme de piété ni même à la seule continuité des traditions antérieures, mais à la notion de survie d'un double du mort dans la tombe (id., ibid., p. 174).

Nous ne nous engagerons pas sur la voie glissante de la soi-disante christianisation des pratiques funéraires pour tenter d'explorer les méandres de ces évolutions, tout d'abord parce que celles-ci s'amorcent bien avant la christianisation de l'Empire et ensuite parce que les attestations de repas funéraires en contexte de sanctuaire, par l'iconographie et les vestiges matériels de l'archéologie, battent en brèche l'hypothèse d'un quelconque rapport entre la religion choisie et la pratique ou l'abstention du repas funéraire. Enfin, les historiens ont suffisamment démontré que l'Église ne définit aucun rituel des funérailles et n'assure pas, en tant que communauté, un culte qui continue à relever de la famille, la liturgie funéraire n'apparaissant pas avant les VIII ${ }^{\mathrm{e}} \mathrm{IX}^{\mathrm{e}}$ s. (Treffort, 1996, p. 141-143 ; Rebillard, 2001, p. 159). Elle n'intervient guère que pour s'intéresser aux tombes des martyrs. Les continuités des pratiques traditionnelles observées dans nos séries archéologiques sont d'ailleurs probablement révélatrices de ce désintérêt de l'Église paléochrétienne pour les funérailles, tandis que la variabilité des coutumes reflète, comme au Haut-Empire sans nul doute, en grande partie la dévolution des funérailles à la famille.

Par ailleurs, si la «tombe chrétienne » n'existe pas vraiment dans l'Antiquité tardive, identifier a priori les « tombes de chrétiens » est un leurre. À Lyon, évangélisée dès le $\mathrm{II}^{\mathrm{e}} \mathrm{s}$. et siège de l'évêque dès le $\mathrm{IV}^{\mathrm{e}} \mathrm{s}$., il n'y a pas de tombes chrétiennes avérées avant le $\mathrm{IV}^{\mathrm{e}} \mathrm{s}$. et, encore, elles ne le sont que par leur situation en contexte de sanctuaire, dont la basilique de Saint-Irénée ou celle de Saint-Just supposées abriter des martyrs. Ces tombes ne se distinguent pas en tout cas, de la plupart des autres tombes fouillées par ailleurs à Lyon (Reynaud, 1998). Comme le souligne justement C. Raynaud, la tombe de chrétien n'est perceptible que dans la topographie des lieux funéraires (Raynaud, 2006, p. 155).

Les historiens de l'Antiquité tardive évoquent des discussions susceptibles de nous intéresser, parce qu'elles ont trait à des remises en question de certains aspects des rites.

Tout d'abord, l'affaire du sacrifice, qui constitue le fondement des cultes religieux et funéraires des Romains et est prolongé par le banquet, apparaît en pleine évolution. Jusqu'à son interdiction à la fin du $\mathrm{IV}^{\mathrm{e}} \mathrm{s}$., sa pertinence est en effet débattue dès le II $^{\mathrm{e}} \mathrm{s}$. et durant le III ${ }^{\mathrm{e}} \mathrm{s}$. (Stroumsa, 2005, p. 108-109).

Ensuite, la question du repas funéraire dans l'Antiquité tardive a été soulevée lors de nombreuses discussions, tant dans l'Antiquité-même (textes chrétiens en l'occurrence) que chez les historiens de la période (Février, 1984 ; Mac Mullen, 1998, p. 92-94 et p. 153-157 ; Rebillard, 2001 et 2003, p. 162-174 ; Stroumsa, 2005). L'enquête très complète réalisée par P.-A. Février dans la littérature antique et les données archéologiques d'Europe et d'Afrique témoignent sans ambiguïté que les repas funéraires continuent durant l'Antiquité tardive, ces derniers étant abondamment illustrés par l'iconographie (peintures, sarcophages) et les objets placés dans les tombes (Février, 1983 et 1984). Il est toutefois difficile de savoir auquel des repas funéraires ces différents textes se réfèrent : celui des funérailles ou celui du culte des morts ? Si certains exemples cités par l'auteur, comme celui de dispositifs à libation ou de vases scellés dans le mécanisme de fermeture de la tombe, pourraient être rapportés aux rites de commémoration dans un cas et, peut-être, au rite de l'ensevelissement dans un autre cas, la question n'est pas traitée en ce sens. É. Rebillard n'évoque quant à lui le repas funéraire qu'en référence aux rites de commémoration du neuvième jour et a posteriori (Rebillard, 2003). On note que l'option de la commémoration funéraire est également choisie par A. Barbet pour interpréter une scène de banquet, datée du milieu du $\mathrm{IV}^{\mathrm{e}} \mathrm{s}$. de notre ère, représentée sur un tombeau de Constantza en Roumanie (Barbet, 1998, p. 111).

Qu'en est-il du repas des funérailles ? Si nos configurations archéologiques régionales ne laissent nul doute sur la réalité de la pratique d'un repas funéraire (mobilier constitué de vaisselle et présence, dans les ensembles funéraires, de structures qui évoquent directement les repas funéraires et les rites de commémoration, en l'occurrence des fours et des conduits à libation : voir chapitre I, 
p. 65-69), l'étape à laquelle ces vestiges se réfèrent pose question. Il nous faut alors reprendre ici les points principaux de notre analyse, relatifs au rôle des dépôts impliqués dans les divers moments qui composent les rites funéraires. Considérons, d'une part, l'abandon de la crémation et, avec elle, la disparition de l'apparat le plus ostentatoire des funérailles stricto sensu, puis, d'autre part, la parenté relevée entre le mobilier des inhumations et le mobilier secondaire des dépôts de crémation que nous interprétons, pour reprendre l'expression de J. Scheid, comme la «pétrification du défunt dans un banquet permanent " (Scheid, 2005, p. 188), en l'occurrence celui des commémorations. Doit-on en conclure qu'avec le passage généralisé à l'inhumation, le repas primaire des funérailles (silicernium), qui traduit le partage tripartite (le mort, les vivants et les dieux) et inaugure les relations futures avec le mort, a perdu son importance au profit des repas a posteriori qui, destinés à renouer les relations entre la famille et les autres membres de la Cité, s'inscrivent dans un système d'échanges plus larges ? Cependant, si les bris de vases, observés dans quelques tombes (le Pillon, Malbosc, la Labre...), se rapportent bien au banquet primaire comme nous l'avons proposé, ils signifient que la pratique du silicernium n'a pas disparu.

D'autres textes, également de même source chrétienne, dénoncent à la fin du $\mathrm{IV}^{\mathrm{e}} \mathrm{s}$. le sacrifice de l'eucharistie en présence du cadavre et le don qui en est fait au mort, ce qui laisse supposer un rapport entre l'eucharistie et le silicernium des funérailles (Rebillard, 2001 et 2003, p. 155-160). Toutefois, les modalités du rite sont trop peu explicites, de même que celles qui se rapportent à son intervention lors des Parentalia, pour envisager un glissement des repas funéraires traditionnels vers le repas eucharistique (Rebillard, 2003, p. 168). Que signifient alors toutes ces discussions sur l'eucharistie et quelle est leur relation avec celles qui se rapportent à la question du banquet funéraire et à celle du sacrifice ? La tentation est grande, en effet, d'envisager qu'est ainsi déplorée une possible confusion opérée par les individus entre un repas social et le sacrifice-banquet propre au monde païen. On rappellera à cet égard un texte de Zénon qui dénonce les sacrifices en tant que pratiques cultuelles au troisième quart du $\mathrm{V}^{\mathrm{e}} \mathrm{s}$. (id., ibid., p. 165). Par ailleurs, la question n'est pas de discuter la légitimité du repas funéraire, ce que ne font pas les textes, mais plutôt la manière dont il se déroule, comme le souligne bien P.-A. Février à propos d'un texte de saint Augustin (Epistulae, 22, 6 ; extrême fin du IV ${ }^{\mathrm{e}}$ s.) : «Ce que critique Augustin [...] c'est la réalité ou la matérialité du repas et de ses excès »(Février, 1984, p. 171). Le texte des Confessions
(6, 2, 2, cité par Rebillard, 2003, p. 168), qui met en scène la célébration idéale des Parentalia, le confirme bien : une seule coupe de vin «fortement trempé d'eau » est utilisée pour plusieurs tombes et partagée avec les parents présents. C'est manifestement la démesure qui est condamnable et donc bien avant tout de l'image sociale dont il s'agit et non pas de la croyance ou des croyances qu'impliquent le repas funéraire. Concernant ces dernières cependant, É. Rebillard cite un passage de De spectaculis de Tertullien (début du III $^{\mathrm{e}} \mathrm{s}$.) qui souligne que c'est le sacrifice aux dieux et les offrandes aux Mânes qui sont rejetés et non pas le repas funéraire lui-même, dont l'obligation d'y participer est, pour les chrétiens, de nature familiale et sociale (Rebillard, 2003, p. 164).

L'ensemble de ces textes nous informe surtout que l'on est toujours, pour ce qui concerne les rites funéraires, dans le cadre d'une pratique sociale et que la diversité des usages ne doit donc pas seulement être mise en relation avec le caractère privé des funérailles, mais aussi avec les diverses options existantes dans la société tardo-antique.

On ne saurait alors qualifier de discordants des faits qui, de toute évidence, même s'ils nous apparaissent contradictoires, ne s'opposaient pas forcément dans la société du $\mathrm{IV}^{\mathrm{e}} \mathrm{s}$.

Ce n'est pas la pratique du repas, que l'on tente de faire disparaître, mais plutôt la manière de faire qui change. Le fait de le marquer ou non dans la tombe et, au $\mathrm{V}^{\mathrm{e}} \mathrm{s}$., la disparition brutale de ses attributs, dans ces dernières, illustrent-ils cette différence qu'il convient alors d'opérer entre le repas communautaire entre vivants pour commémorer les morts et dont ils pourraient progressivement en être bel et bien exclus et les pratiques anciennes du repas tripartite, partagé ? Le sacrifice n'est-il plus représenté que par le volatile, fréquemment placé dans les tombes tardo-antiques, comme l'image d'un «mini-sacrifice » peu sanglant? Le vase unique, à liquides en l'occurrence, relevé dans la majorité des tombes de l'Antiquité tardive n'est-il plus qu'un rappel du rite plutôt que sa mise en scène effective ? Enfin, sa disparition dans le courant $\mathrm{du} \mathrm{V}^{\mathrm{e}} \mathrm{s}$. (selon les régions) peut-elle être mise en relation avec l'interdiction des cultes païens par Théodose en 391-392 ? On se gardera dans tous les cas de réduire un phénomène à un autre, l'absence de support n'impliquant pas l'abandon du rite, et l'on doit sans doute plutôt envisager que l'on est passé à un autre mode d'expression, dont l'archéologie n'a pas gardé les traces. Dans les scènes relevées dans les catacombes romaines, le repas est sur une table ce qui, selon la tradition romaine, le rapporte à celui des vivants. Ainsi les vivants mangent... 
Partagent-ils pour autant le repas avec le mort ? La question se pose à propos des contextes de basilique de nos régions, caractérisés par l'extrême rareté sinon par l'absence de vases dans les tombes, mais par la fréquente présence de vestiges de repas et de vases situés hors des tombes, voire dans des fosses à part et des fours à pain. Ces indices sont certes faibles pour envisager que le banquet funéraire soit en train de changer complètement de sens et donc de rôle, mais peut-être sont-ils le signe que certains individus s'engagent progressivement dans une autre voie.

Le repas funéraire pourrait alors avoir acquis une autre dimension ou une autre raison d'être. L'importance que semble prendre la commémoration tend à indiquer qu'il s'oriente de plus en plus vers une action de cohésion de la communauté, en se détachant alors de son rôle de restauration du normal dont l'objectif était de maintenir la stabilité sociale et l'équilibre entre les vivants, les dieux et le mort, et d'accompagner le mort dans les étapes de son passage. En somme, le christianisme pourrait ne pas s'être tout simplement accommodé des repas funéraires, mais avoir fait plus que cela. En effet, pour P.-A. Février, il pourrait y avoir une sorte de "récupération » du repas funéraire par les chrétiens : les repas de commémoration sur les tombes, qui s'accompagnent d'un partage et d'un don aux autres, seraient devenus le "lieu d'évergétisme chrétien » (Février, 1977 , p. 42). Nous y verrions même, pour notre part, le prolongement de l'action de l'évergétisme funéraire du HautEmpire, instauré par les riches pour entretenir quant à eux leur mémoire (Schmitt-Pantel, 1982). Le discours tardoantique est toutefois ici différent : sur ce point-là, il semble être moins question d'image sociale que d'humanité et de salut de l'âme. Plus que de la survie du défunt, c'est l'unité du groupe qui est visée dans le repas funéraire de commémoration de l'Antiquité tardive, tandis que plus largement, sur la tombe du martyr, la mémoire du défunt, qui entretient un modèle de vie et de pensée, agit comme le pivot de cette cohésion. Un tel glissement des traditions dans un discours nouveau est un phénomène classique et on ne peut s'empêcher de songer, inversement, au retour à la norme, prôné par Julien l'Apostat au milieu du $\mathrm{IV}^{\mathrm{e}}$ s., qui tente de restaurer les traditions séculaires en réactivant les rites et les pratiques tombées en désuétude afin d'assurer la survie de l'Empire ${ }^{54}$ (Cabouret, 2007). En s'appuyant sur la tradition

54. B. Cabouret, «Quelles normes religieuses à l'époque tradive ? L'exemple de Julien l'Apostat et de son entourage ", communication donnée au colloque organisé par B. Cabouret et M.-O. Laforge (dir.), «La Norme religieuse dans l'Antiquité», 14-15 déc. 2007, Maison de l'Orient méditerranéen, Lyon. gréco-romaine de la philanthrôpia et rappelant que l'évergétisme est une pratique de la société antique, il recommande les relations d'assistance entre les individus à l'imitation des chrétiens, tout en restant dans un cadre civique. Par ce jeu au cours duquel on se redistribue ou se dispute traditions et innovations, nous parvient l'image d'une grande diversité de pratiques qui, au fond, n'illustrent que des variations sur un même thème et ne traduisent qu'en partie une diversité d'objectifs.

\section{DE L'IMAGE SOCIALE VERS L'IMAGE DE SOI}

Tout semble indiquer qu'une partie des éléments qui vont entrer dans la constitution du système funéraire antique s'amorce très tôt dans La Tène finale et se précise dans le courant $\mathrm{du} \mathrm{I} \mathrm{I}^{\mathrm{er}} \mathrm{s}$. avant notre ère dans divers secteurs géographiques. On en reprécisera les différentes étapes : mise en place du banquet funéraire, émergence du bûcher en fosse dans l'aristocratie et d'une gestion polymorphe de ses vestiges, rationalisation des modalités de dépôt du mobilier à La Tène finale, puis généralisation de la crémation autour de l'ère et apparition des grands monuments, explosion du bûcher ostentatoire et uniformisation manifeste des pratiques au $\mathrm{I}^{\mathrm{er}}$ s., développement de monuments funéraires et perte d'importance du bûcher vers la fin du $\mathrm{II}^{\mathrm{e}} \mathrm{s}$, disparition de la crémation dans la seconde moitié du $\mathrm{III}^{\mathrm{e}}$ s. et des monuments à la fin de ce siècle, apparition de nouvelles formes d'espaces funéraires au $\mathrm{IV}^{\mathrm{e}} \mathrm{s}$. et, enfin, disparition totale de l'appareil traditionnel du banquet au siècle suivant. Ces comportements s'organisent en une sorte de rythme qui commence autour du $\mathrm{II}^{\mathrm{e}}$ s. av. J.-C., avec la mise en place de pratiques que l'on retrouve jusqu'à la fin du IV ${ }^{\mathrm{e}}$ s. apr. J.-C. dans des proportions variables, avec des aspects qui prennent plus ou moins d'importance selon les moments. L'ensemble des transformations relevées au cours de ces cinq siècles s'inscrit donc dans la continuité et transcrit moins des ruptures que des évolutions, puisqu'à chaque fois les modifications se traduisent par une différente mise en système d'éléments déjà en place, des gestes proches, des expressions en apparence identiques, pouvant transcrire des discours divergents. De La Tène finale à la fin de l'Antiquité, les rites funéraires évoluent par la transformation de divers aspects de leurs pratiques, selon des rythmes dissemblables. Tous n'évoluent pas en même temps, mais il s'opère des glissements d'un registre à l'autre, illustrés par des emprunts, des réinterprétations et des innovations, conférant à l'ensemble un certain nombre de continuités au sein de la discontinuité. 
Du I $^{\text {er }}$ s. au III ${ }^{\mathrm{e}}$ s., l'inhumation et la crémation coexistent sans que l'essentiel du rite funéraire ne diffère selon l'une ou l'autre pratique, puisque de nombreuses structures montrent que les mêmes gestes sont relevés quel que soit le traitement du corps. En réalité, depuis La Tène finale, la seule différence réside en la prédominance de l'une ou de l'autre de ces pratiques selon les moments et les régions, tandis que les matériaux du rite paraissent varier et évoluer en fonction des milieux sociaux et des coutumes locales.

Cependant, la disparition de la crémation, à l'aube de l'Antiquité tardive, peut indiquer une volonté de traduire les étapes de la séparation de manière simplifiée, soit parce qu'une partie d'entre elles ne signifie plus rien, soit parce que seules sont retenues celles qui apparaissent fondamentales dans une idéologie qui évolue. Nous interprétons le choix de l'inhumation au Bas-Empire comme le signe d'une modification de l'image sociale, qui prend source dans la seconde moitié du $\mathrm{II}^{\mathrm{e}} \mathrm{s}$. avec l'abandon du bûcher ostentatoire, et se poursuit dans le courant du $\mathrm{III}^{\mathrm{e}} \mathrm{s}$. avec la disparition des grands tombeaux. Parce que l'ostentation est moins d'actualité, la crémation ne correspond plus aux attentes des vivants, c'est-à-dire à l'image que la société et les individus veulent donner d'eux-mêmes. En aucun cas, cette option ne peut être rapportée à la christianisation de l'Empire. D’une part parce que, tout comme la généralisation de la crémation en Gaule semble antérieure à l'achèvement de la conquête (bien que le «vide sépulcral » relevé autour de l'ère reste à expliquer), la « simplification » de l'apparat funéraire et le passage à l'inhumation exclusive sont antérieurs au début du $\mathrm{IV}^{\mathrm{e}} \mathrm{s}$., sachant en outre que la population est encore, à ce moment-là, majoritairement païenne ; d'autre part, contrairement à l'idée reçue, les chrétiens des premiers temps ne pratiquent pas l'inhumation en référence à la résurrection des corps ; la question du choix de l'une ou l'autre pratique est discutée dès la fin du $\mathrm{II}^{\mathrm{e}}$ s. et doit être mise en relation avec ce nouveau souci porté au corps et qui, selon É. Rebillard, trouve un écho à la fin du $\mathrm{III}^{\mathrm{e}} \mathrm{s}$. dans le fait que l'atteinte aux restes humains constitue un crime sanctionné dès le milieu du $\mathrm{V}^{\mathrm{e}} \mathrm{s}$. (Rebillard, 2003, p. 101). C'est une fois encore en contexte urbain, et donc sans doute dans les classes relativement privilégiées, que semblent se produire les changements de pratiques. Les données de la région Rhône-Alpes montrent en effet que c'est à Lyon que l'inhumation prend très tôt son essor, alors que dans le monde rural on bascule plus tardivement, et donc plus brutalement, dans cette pratique, tandis que les usages traditionnels des funérailles élaborés dans le rite de la crémation y sont plus volontiers transposés dans les inhumations. Cette hypothèse peut être argumentée par le fait que les premiers sarcophages chrétiens lyonnais, du début du $\mathrm{III}^{\mathrm{e}}$ s., sont importés d'Italie avant d'être fabriqués dans une pierre locale (Février, 1983, p. 33).

L'ostentation de l'appareil funéraire n'apparaît plus qu'un souvenir, comparé à ce qu'elle était au début de l'Empire. Toutefois, la disparition de ses indices archéologiques évidents ne doit pas masquer sa probable réalité : la différence tient à qu'elle se retrouve de nouveau, comme au début de l'ère, aux mains des classes privilégiées. En effet, comme le souligne C. Raynaud, mausolées et sarcophages richement décorés sont réservés à une mince frange de la société (Raynaud, 2006, p. 149), tandis que la transformation de certains de ces monuments en sanctuaires indique que cette élite s'exalte dans les contextes chrétiens. Gloire terrestre et gloire céleste s'accommodent. Une grande part de l'appareil étant soustrait aux regards, les funérailles paraissent cependant plus intimistes, ou plutôt la mort est nettement moins extravertie : on entre dans un processus d'individualisation de la mort. À noter cependant que les obsèques impériales conservent les formes traditionnelles romaines durant tout le $\mathrm{IV}^{\mathrm{e}} \mathrm{s}$. (Belayche, 2001, p. 152), ce qui prouve que les funérailles transcrivent bien encore l'image sociale idéalisée, à savoir ici celle de l'Empire.

Signe d'une dissolution sociale ou, plus probablement, de la désintégration du modèle civique, l'image qu'offrent les pratiques funéraires quotidiennes de l'Antiquité tardive s'écarte sensiblement du modèle qui prévalait au cours des deux premiers siècles de notre ère. Bien que dans ses structures fondamentales le monde tardo-antique n'ait guère changé, et cela en dépit de la conversion de l'Empire, l'individu semble toutefois s'y inscrire d'une manière différente. Du point de vue des pratiques funéraires, cette évolution entraîne deux attitudes qui ne sont antinomiques qu'en apparence. L'une se réfère à des coutumes et l'autre amorce de nouvelles pratiques sociales et une nouvelle forme de piété, même si ces dernières puisent de toute évidence leur source dans les premières. L'ensemble des données traduit une coexistence, plutôt qu'une opposition, entre les traditions et les innovations ; c'est ainsi que l'on se dispute sur le sens et le contenu des rites, mais pas sur leur maintien. Pour résumer la situation, on se tournera de nouveau vers P.-A. Février lorsqu'il distingue la mort vécue et la mort attendue, sources d'expressions diverses et contradictoires réunissant la force des traditions et la pensée chrétienne (Février, 1984, p. 164). 